Interim Report

\title{
Improved Methods for Incorporating Risk in Decision Making
}
M. J. Clausen
D. W. Fraley
R. S. Denning

August 1980

Prepared for

the U.S. Nuclear Regulatory Commission

Pacific Northwest Laboratory

Operated for the U.S. Department of Energy

by Battelle Memorial Institute 
NOTICE

This report was prepared as an account of work sponsored by the United States Government. Neither the United States nor the United States Nuclear Regulatory Commission, nor any of their employees, nor any of their contractors, subcontractors, or their employees, makes any warranty, express or implied, or assumes any legal liability or responsibility for the accuracy, completeness or usefulness of any information, apparatus, product or process disclosed, or represents that its use would not infringe privately owned rights.

\author{
PACIFIC NORTHWEST LABORATORY \\ operated by \\ BATTELLE \\ for the \\ UNITED STATES DEPARTMENT OF ENERGY \\ Under Contract DE-AC06-76RLO 1830
}




\section{2}

INTERIM REPORT

IMPROVED METHODS FOR INCORPORATING RISK IN DECISION MAKING

M. J. Clausen

D. W. Fraley

R. S. Denning

August 1980

Prepared for

the U.S. Nuclear Regulatory Commission, Probabilistic Analysis Section under a Related Services Agreement with the U.S. Department of Energy Contract DE-ACO6-76RLO 1830

FIN NO. B2279

Pacific Northwest Laboratory

Richland, Washington 99352 
. 
CONTENTS

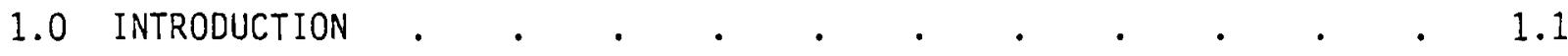

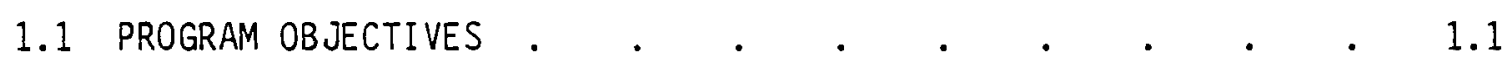

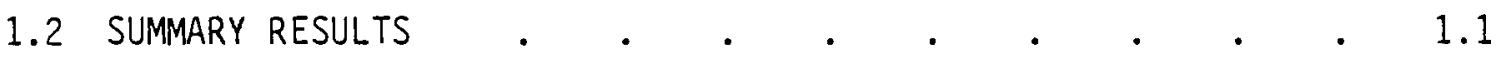

1.3 TOPICS REQUIRING FURTHER INVESTIGATION $\quad . \quad \ldots \quad . \quad . \quad . \quad 1.3$

2.0 METHODOLOGICAL APPROACHES TO DECISION MAKING ..$\quad$. $\quad$ • $\quad$. 2.1

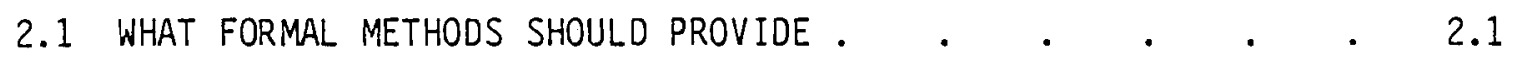

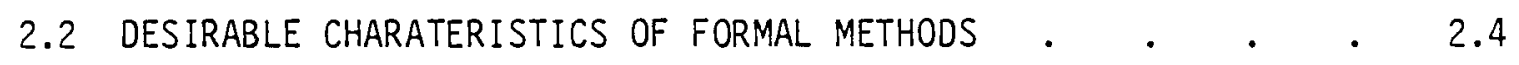

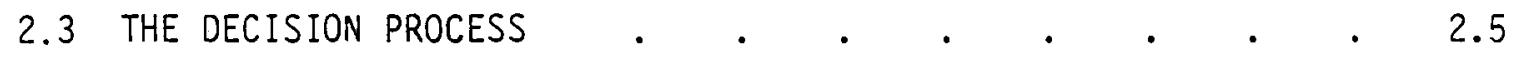

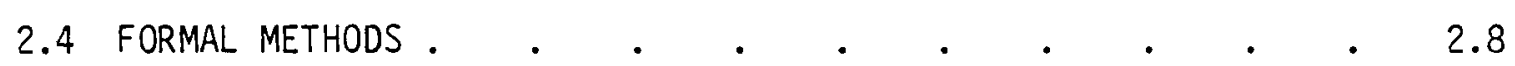

3.0 SELECTING A FORMAL METHOD $\quad$.

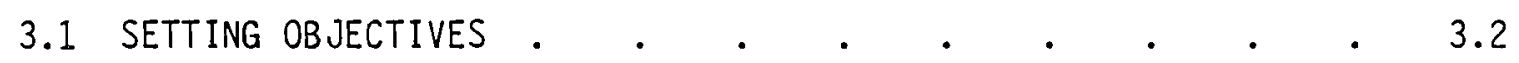

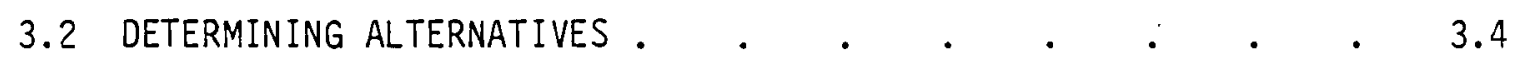

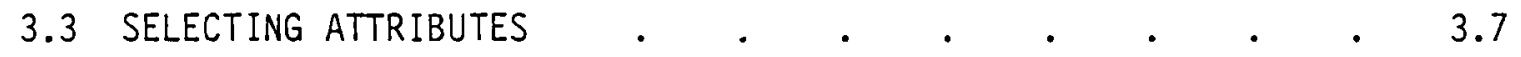

3.4 SYNTHESIZING AN OBJECTIVE FUNCTION •

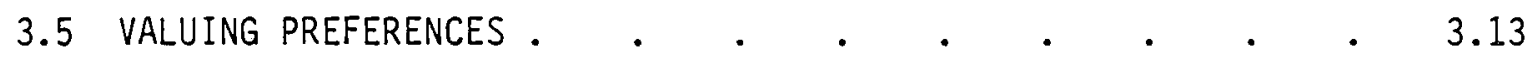

4.0 THE MEASUREMENT OF RISK.$\quad \ldots \quad$.

4.1 SURVEY OF THE USE OF RISK MEASURES IN REGULATORY
DECISION MAKING

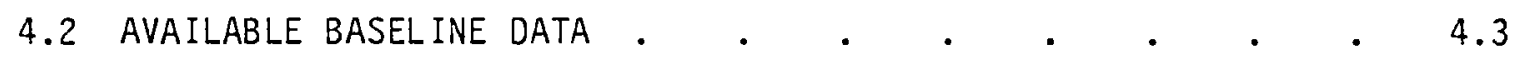

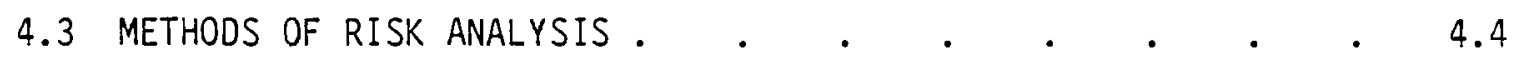

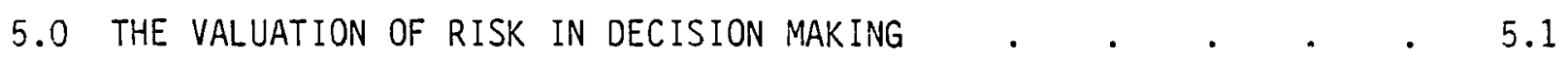

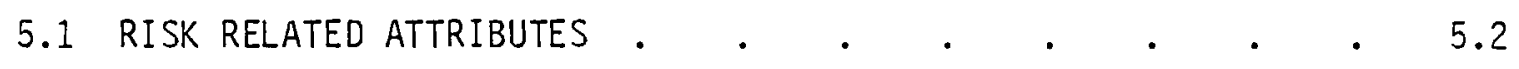

5.1 .1 Human Health Effects . . . . . . . 5.2

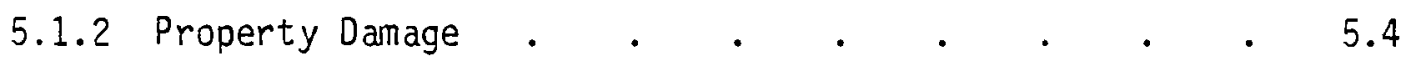

5.1.3 Aesthetics/Environment . . . . . . . . . 5.5 
5.2 PROBLEMS WITH AND INSIGHTS INTO THE SELECTION AND WEIGHTING OF ATTRIBUTES.$\quad \cdot \quad \cdot \quad \cdot \quad \cdot \quad \cdot \quad \cdot \quad \cdot 5.5$

5.2.1 What Is the Relative Importance of Risk Attributes? . 5.6

5.2.2 Who Is At Risk? . . . . . . . . . 5.9

5.2.3 How Does the Timing of Consequences Affect Their
Value? . . . . . . 5.10

5.2.4 How Do Uncertainties Affect the Use of Risk
in Decision Making . . . . . . . . 5.12 REFERENCES

BIBLIOGRAPHY • 


\section{FIGURES}

2.1 Sequence of Events in Developing Decision Methodologies a $\quad 2.6$

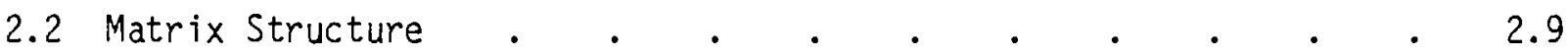

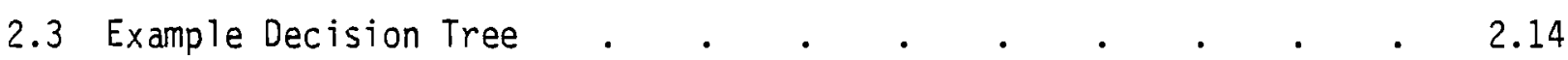

3.1 Setting Objectives . . . . . . . . . . . . . . . . . 3.3

3.2 Determining Alternatives .

3.3 Select Attributes . . . . . . . . . . . . . . . 3.8

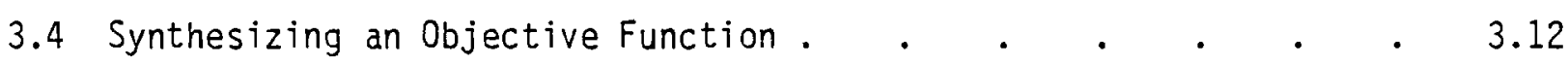

3.5 Valuing Preferences .

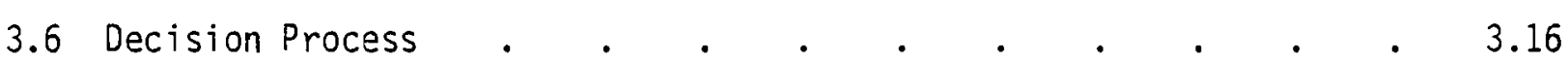

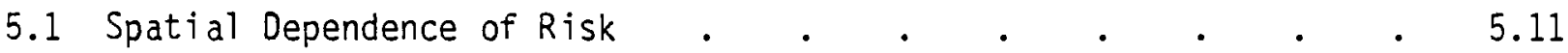

5.2 Discounted Fatalities as a Function of Delay Period,
Plateau Period, and Discount Rate . $\quad . \quad$. . . . . . 5.13

5.3 Cumulative Probability Distribution Functions on Total
Utility for Seven Alternatives $. \quad . \quad . \quad . \quad . \quad . \quad$

5.4 Distribution Functions for Weighted Consequences with
Confidence Intervals $\quad . \quad \cdot \quad \cdot \quad \cdot \quad . \quad . \quad . \quad 5.16$

\section{TABLES}

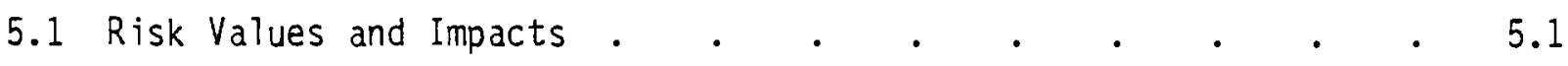

5.2 Comparison of the Importance of Weighted Attributes . . 5.6 


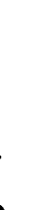

$\cdot$ 


\subsection{INTRODUCTION}

\subsection{PROGRAM OBJECTIVES}

This paper reports observations and preliminary investigations in the first phase of a research program covering methodologies for making safetyrelated decisions.

The objective has been to gain insight into NRC perceptions of the value of formal decision methods, their possible applications, and how risk is, or may be, incorporated in decision making.

The perception of formal decision making techniques, held by various decision makers, and what may be done to improve them, were explored through interviews with NRC staff. An initial survey of decision making methods, an assessment of the applicability of formal methods vis-a-vis the available information, and a review of methods of incorporating risk and uncertainty have also been conducted.

\subsection{SUMMARY RESULTS}

Interviews were conducted with a sample of NRC staff to determine their perceptions of the value of formal decision models. The interviews focused on specific applications of formal decision methods and how risk has been treated. They were structured to elicit perceptions of the need and applicability of formal decision analysis. Care was taken to explore areas of specific interest without imposing interviewer bias.

Some results of the interviews are:

- Formal decision methods are not widely understood at NRC.

- Risk and uncertainty have not been not quantitatively introduced into decision making.

- The decision makers and the decision users have different perceptions of the value of formal decision methods.

- The decisions at NRC are complex and varied enough to preclude any generic decision methodology. 
In the sample of NRC staff there appeared to be a limited understanding of formal decision analysis. This seemed to be founded in a lack of experience using decision models. There was little appreciation of the advantages formal methods offer or the process of selecting and using them. There does appear to be interest in better understanding; however, there is also the impression that the use of formal models may wrest control from the decision maker, or that the process will expose them to an additional source of criticism.

Risk and uncertainty are not formally included in the decision making processes in any repeatable manner. There appear to be two problems in dealing with risk. First, the specific objective of reducing risk does not involve any explicit tradeoffs with cost. Often reduction in risk is pursued no matter how significant or costly. Second, the measurement of risk, risk reducton, risk reduction potential, minimization of consequence and so forth is difficult. Frequently, the scale is subjective (e.g., low, medium, high) or only provides some qualtitative discussion of the need to recognize risk. When the risk reduction appears likely, then the decision usually favors pursuing the action without examination of the overall risk to the public or considering the net cost of the proposed change.

Dealing with uncertainty in the decision making process, or with uncertainty in the information, which is the basis for the decision, is difficult. Uncertainty in the values to be used also results in selecting imprecise (e.g., subjective) scales. The available techniques which deal with uncertainty are not widely known and are still evolving; therefore, there is little appreciation of these techniques.

NRC Organization presents an interesting decision making information problem. Decision makers are involved in evaluating the information bases for their decisions and are intimately familiar with them. As a result they feei very little need to document these bases by using a formal decision model, and they feel there is little loss in the quality of the decisions. However, the decisions are of ten implemented or defended by other branches of the NRC. Those who must implement or defend the decision place considerable value on the information provided by use of formal decision methods. They can better use decisions when the alternatives considered, the values assigned to the 
attributes, the criteria for performance, and the objective of the decision process, are all documented for reference. Knowing whether or not an alternative was considered or why it was not the preferred option can minimize the need for replicating the whole process from scratch. This documentation provides much information about the reasons for discarding alternatives and about what was or was not considered should additional examination of the problem be warranted. These are especially valuable if the decision makers leave or change assignments.

Many interviewees indicated that simple decision models, if they were available, would find wider use. They also hoped to find a generic "do everything" decision model for all NRC decision making. Discussions indicate that the range and scope of decision applications is varied and complex. Therefore, it is unlikely that a single decision model would be appropriate for all applications. The requirements of the situation define the requirements of the decision model.

\subsection{TOPICS REQUIRING FURTHER INVESTIGATION}

A number of problem areas have been identified. They range from a general lack of familiarity with available formal methodologies to specific difficulties in measuring and valuing risk.

It is useful to view the decision making process at NRC as an information problem. Better information is necessary as a first step to better decision making. The need for better information has two distinct aspects:

1. Information about decision making methods should be made more available to decision makers; this includes:

- selecting an appropriate method

- the resulting benefits

- possible difficulties in its application.

2. Information necessary to make a decision, particularly in describing uncertainty, should be improved: this includes:

- using information concerning risk

- developing better descriptions of risk

- evaluating the associated uncertainties. 
The first information problem can be resolved in part by communication with decision makers and in part by their perception of need for improved methods. For the first part, the complicated terminology often associated with formal decision analys is methods must be made clearer. Additionally, successful applications must be exhibited. This requires a willingness on the part of the decision makers to apply the methods.

Increasing the awareness of decision makers about formal decision methods is an evolutionary process. As more successful applications of formal methods become available, they should become more acceptable. To a degree, this process has already occurred. Various NRC branches commonly conduct formal analysis in the form of value-impact assessments for regulatory decisions.

In this paper, we have begun to address the communication of information about formal decision methods. In Chapter 2, formal methods are reviewed with respect to:

- what they should provide

- their characteristics

- the key elements of a formal process (terminology)

- how the principal approaches differ.

In the third chapter many of the questions and considerations associated with selecting or designing a formal analys is are addressed. This discussion represents the results of our review of formal methods.

Specifically, the various formal approaches require further clarification by example. These examples should be oriented toward illustrating the usefulness of each formal methodology.

Further efforts in making better information available about formal methods might include:

1. Develop a framework for assessing the need for formal analysis.

2. Develop a handbook that provides example analysis.

3. Provide guidelines for applying decision analysis methods.

4. Structure the process of determining decision criteria.

Each of these suggested areas deals with communicating information about decision making methods. However, because the implementation of improved methods 
is also based on perceived need, the efforts should be focused on making better information available for decisions.

Our finding, discussed in Chapters 4 and 5 , is that risk information pertinent to many important decisions remains inadequately characterized.

Development of Risk Measures

Potential problem areas have been identified relating to the use of risk as an attribute in decision making. Risk analysis for nuclear systems is an immature methodology. Analysis has only been performed in significant depth for two plant designs which have limited applicability to the population of U.S. reactors. Risk analysis methods are also going through a period of innovation and evaluation, and it is not clear at this time what depth of analysis is required to satisfy a given objective.

A second source of problems involves weighting of risk-related attributes. Public concern about reactor safety involves emotionalism to a greater degree than an objective assessment of comparative risks. The question of how or to what extent public perceptions should be used in weighting risk is a controversial issue. finally, risk measurement alignment involves large inherent uncertainties that can make it difficult to differentiate between alternatives in a meaningful way in arriving at a decision.

A number of related studies should be undertaken that would provide a basis for guidelines for the use of risk analysis in decision making. The studies should be undertaken within the context of a few specific risk-based decisions. The specific examples selected should be varied in type (e.g., prioritization of research topics in comparison to a back-fit decision) in order to evaluate the generic applicability of methods. For each example, the following tasks would be undertaken.

1. Develop The Framework for the Analysis

The framework depends upon the specific application. This effort requires the selection of a baseline, grouping of reactors into generic models, definition of the timescale for the analysis, choice 
of accident sequences, and selection of alternatives for evaluation. Variations in framework should be made in order to evaluate the effect on the decision made.

2. Select Risk Methodology

Methods of analysis would be selected for estimating the probabilities and consequences of accident sequences. Different depths of risk analysis would be undertaken in order to evaluate the effect on the decision. Estimates of the effort required by each approach would also be made.

3. Select Criteria and Develop Methods for Valuing Criteria Weighting functions are required both as a function of criteria level and between criteria. Consideration would be given to the measurement of public preference and if necessary, surveys would be undertaken. Discussions should also be held with NRC officials to determine whose values should be represented in the weighting of criteria. The choice of different weighting schemes is expected to affect the decisions made. The extent to which the decision may be changed would be examined.

4. Develop Methods for Making Decisions in the Face of Uncertainty Methods have been previously developed for comparing distribution functions. These methods would be extended to obtain ordering techniques for distribution functions that have large associated uncertainty bands (variance). Uncertainties would be estimated for the calculated level of risk for each alternative. The sensitivity of the decision process to the magnitude of uncertainty would be investigated. 


\subsection{METHODOLOGICAL APPROACHES TO DECISION MAKING}

This chapter presents the chief features of formal decision methods. These are well documented and summarized in the literature. For this reason, the discussion is oriented to the potential for application of each method.

From the viewpoint of the decision maker, decision making involves the processing of information. The form, content, and level of detail of the information often dictates the applicability of formal methods. conversely, the application of a certain method is dependent on the available information. In each methodology, the final objective is the same: selecting a preferred course of action that accounts for all factors that are important in the context of the decision that must be made.

Decision problems are usually partitioned according to whether a decision is made under conditions of:

- certainty - Where the outcome of the decision is known.

- uncertainty - Where possible outcomes may be unknown.

The process begins with the identification of objectives that define the decision problem and the goals of the best solution. At the onset, the objectives can be described as general, qualitative statements, such as "improve productivity" or "reduce risks." Next, the availability of information that will affect the decision is considered.

The form, content, and level of detail of the available information will dictate the application of formal methods. This determination is at the nucleus of the application of any formal approach. Chapter 3 deals with this important consideration.

\subsection{WHAT FORMAL METHODS SHOULD PROVIDE}

Appropriate decision methodologies must exhibit a particuiar set of characteristics in order to accurately depict the process of decision making. In attempting to understand a decision problem the decision maker is faced with several types of issues. The selection of a formal decision method should be based on its ability to resolve the following issues. 
Uncertainty - A key issue, mentioned above, is the uncertainty of the information on which the decision is to be made.

A decision method should provide a way to explicitly characterize the uncertainties associated with the decision and to revise this description as additional information becomes available. For decisions under uncertainty, traditional approaches utilize probabilistic techniques.

Generally, decision makers are not completely ignorant about the likelihood of important events, but they are uncertain about the probabilities. Formal methods that incorporate uncertainty are built on the premise that it is rational to incorporate prior hunches, convictions, or information about the likelihood of varius outcomes. This is accomplished by converting available information into a subjective probability distribution. The use of a probabilistic description of outcomes is of ten referred to as "decision making under risk."

A formal method should also provide an assessment of the value of more information. Among practitioners, this is of ten referred to as establishing the "value of perfect information." In decisions involving uncertainty it may be possible, at some expense, to gain more information, thus reducing uncertainty. The first step in this process is to determine the value of better information. If better information is of little or no value, then its expense may not be justified. Formal methods dealing with uncertainty provide approaches for making these tradeoffs.

Preferences - Specification of a decision problem involves two different types of information. One type of information quantifies the outcomes associated with each alternative decision under consideration. The other type describes the desirabilities of each of the outcomes. Decision methods should provide a structure to formally value these preferences.

Formal methods provide ways to capture a decision maker's preferences for the relative desirability of outcomes in a form suitable for analysis. The most of ten used measure, "benefits," can be assessed by establishing a "utility" value for benefits. In effect, the conventional "rules of thumb" of ten used in valuing outcomes are transformed into a consistent structure. 
Additionally, formal methods allow the explicit identifiction of possible biases or inconsistent value judgments. For example, a decision maker may unconsciously compromise a decision in order to rationalize a prior decision. Formal methods do not allow this inconsistency.

Structure - Decision making in the presence of uncertainty usually involves the processing of significant amounts of information. Without a format to guide the selection and display of such information, the decision maker may be forced to place an unreasonably high premium on simpiicity.

At a minimum, formal methods provide a bookkeeping tool for displaying the model or conceptualization of the decision making problem. This allows the decision maker to be aware of what is currently for consideration. It also allows identification of what is not included, thus allowing for revisions and improvements. Informal models tend to change as the solution process evolves. A formal structure also provides an explicit vehicle for communication among people concerned with the decision.

Sensitivity - Sensitivity of the input information and of the outcomes is often a key factor in selecting a preferred decision.

In formal methods, sensitivity of the alternate decisions to input information or assumptions can be explicitly tested. Important factors that are usually involved in sensitivity analysis are:

- For uncertainty, it is important to test the effect of more information on the outcome and the effect of more certainty about the outcome.

- For the decision maker's preference, it is important to test for possible biases or alternate value systems that might change the decision.

- For the analysis approach or structure it is important to test for gaps or inconsistencies in the model.

Formal decision methods attempt to provide a paradigm that resolves decision problems in a manner consistent with the attitudes and objectives of the decision maker. This is true whether the decision maker is acting for himself, an organization, or the general public. 
The application of a formal decision method is useful if it provides a decision maker increased confidence and satisfaction in making important decisions. It is also useful if it provides better evidence to those who might be affected by the decision.

\subsection{DES IRABLE CHARACTERISTICS OF FORMAL METHODS}

Formal methods make decision processes explicit by describing uncertainty, valuing preferences, providing a structure, and allowing sensitivity analysis. They allow the decision maker to more clearly and consistently process information in the form of:

- assumptions

- objectives

- values

- information needs

- outcomes

- alternative courses of action. The following are criteria that should be considered in selecting a formal method. The method should:

- draw on readily available data for assessment of likely outcomes

- utilize information based on quantitative estimates, thus eliminating subjectivity wherever possible

- provide a structure where cause and effect relationships can be traced through the methodology

- be simple enough to be used by individuals with general technical backgrounds

- be systematic in its characterization and valuation of all important decision factors

- allow comparison of all major advantages and disadvantages

- explicitly deal with uncertainties and supply information on the sensitivity of data and assumptions 
- be broadly applicable to a general class of decision problems if several are under consideration.

\subsection{THE DECISION PROCESS}

Formal decision methods provide approaches for managing the available information about the decision problem at hand. To a degree, each approach has similarities with others. The principal differences are how each deals with uncertainty, values preferences, structures the information, allows sensitivity analysis, and integrates values and impacts.

A useful way to view decision making in a formal manner is to view it as a process consisting of five elements: 1) objectives, 2) alternatives, 3) attributes, 4) objective function, and 5) valuation (Baecher et a1. 1975). This structure is comon to all decisions. How these various factors interrelate is shown in Figure 2.1 .

The process begins with identification of decision objectives. Next, alternative courses of action are listed, one of which represents the ultimate decision. Each alternative decision is designed to meet the general objective.

Objectives for most significant decision problems are often broad qualitative statements. Therefore, the decision maker or analyst must identify a set of criteria for the objective that provides a more quantitative measure of the objective. Each objective (or subobjective) must be completely defined by an associated set of criteria. Next, the attributes that define each alternative are described. These attributes are the measures that are compared with the criteria to define the "best fit" between the alternatives and the objectives.

Tradeoffs of the desirability of attribute performance between alternatives are made through the use of an objective function.

The final element of the decision process is the valuation of desirability of each alternative. This is performed by factoring the decision maker's preferences with the measures of performance of each alternative. 


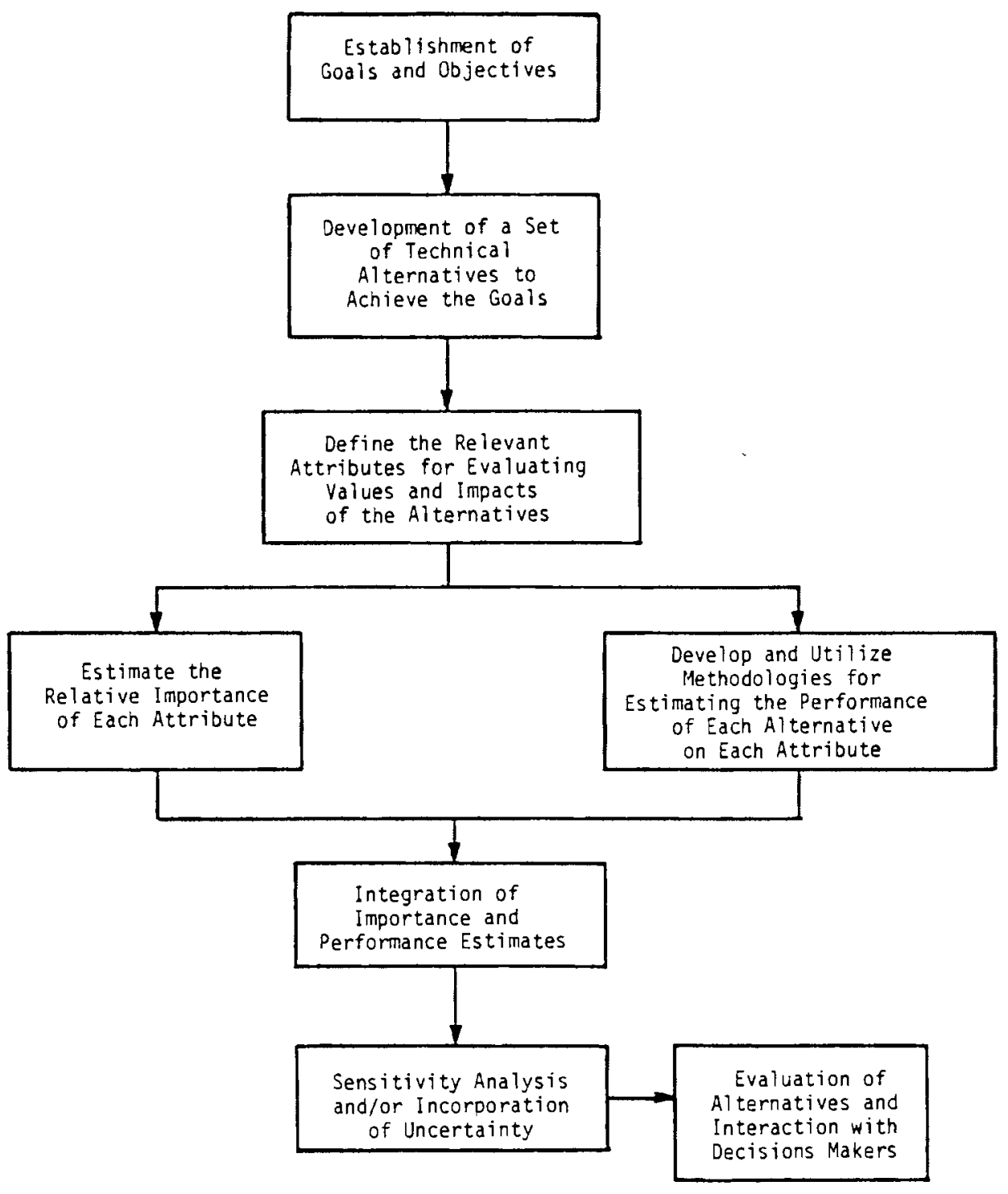

FIGURE 2.1. Sequence of Events in Developing Decision Methodologies 
Dividing the decision process into these five elements does not imply that each is considered in sequence or independently. The definition and assessment of each element is, of necessity, iterative. As new and better information becomes available, a formal method evolves to account for it.

Formal methods are usually distinguished by the method of valuation they use and the form of objective function they specify. The decision maker or analyst must supply the other elements at a level commensurate with the formal method being used. In one way, the available information may dictate the appropriate formal method. Conversely, the application of a specific method makes explicit demands on the form and content of the information it requires.

The following is a brief discussion of the aspects of the elements that are common to the application of any formal methodology. Included are the key considerations in the development of each.

Objectives - These state the goals of the decision. Pertinent to a given decision problem a set of objectives should be identified that are:

- complete, including all of the important considerations that could affect the decision

- of minimum size to facilitate the analysis

- value independent such that double counting is avoided.

Each objective may have several levels of subobjectives which are often referred to as decision criteria. Only at the lowest level will the criteria be specific enough to be dealt with analytically. The number of subobjectives and their breadth at each level is a judgmental problem, of ten dealt with iterative $1 y$.

Alternatives - These are often provided as a given for analysis. In this case, possible insights may be lost that are afforded from restructuring the alternatives as part of the analysis. Similarly, bounds and constraints on the decision serve to delimit the range of possible alternatives. 
- The identification of good alternatives requires the careful specification of the bounds of the decision problem.

Alternatives should be:

- consistent with the objectives

- mutually exclusive

- reasonably competitive

- feasible

- small in number.

Attributes - These measure the performance of alternatives. Attributes that provide measures and criteria to quantify objectives are of ten treated as synonomous. Performance of each alternative on each attribute needs to be estimated; obtaining these estimates is usually the bulk of technical work in the decision process. Attributes should be:

- estimable - e.g., measures are possible

- comprehensive - The degree of realization of an objective by a given alternative is fully expressed by the attributes.

It is also desirable that attributes be:

- value independent - such that the values of performance on several attributes are not interrelated

- minimal - allowing the analysis to remain tractable.

The following section reviews the common formal methods. They differ in the objective function they specify and the approach used for valuation.

\subsection{FORMAL METHODS}

Formal methods for describing and facilitating decision making have been developed to account for the myriad considerations necessary for complex decisions. To a certain extent they have evolved concomitant with the increasing complexity of the decisions being made. Each provides a method of valuation and an associated form for the objective function. The methods range from a set of consistent rules for rational behavior to assessment of uncertainty and determination of utility functions for comparing unlike alternatives. 
There are four broad classes of formal methods: 1) matrix, 2) costbenefit, 3) utility approaches, and 4) decision trees. They differ in how they deal with preferences, in setting relative values between attributes, treat temporal aspects, and in the data they require. Problems that require this valuation are usually referred to as "multi-attributed" decision problems. Here we focus upon the form and content of the decision information necessitated by the methods. The following chapter discusses the applicability of the principal formal methods.

Matrix Methods - These are the most common class of decision structures used as an aid in multi-attributed decisions. The matrix structure, used to present the measures of performance of the attributes on the alternatives, is the basis for the name. The row headings of the matrix correspond to the alternatives and the column headings correspond to attributes. The matrix elements are the associated values of each attribute on each alternative. Here independence between attributes is assumed and desirability is proportional to attribute values. A weight factor is often introduced to characterize this proportionality. This is depicted in Figure 2.2.

\begin{tabular}{cccc} 
Alternatives & 1 & 2 & 3 \\
\hline A & $P_{A 1}$ & $P_{A 2}$ & $P_{A 3}$ \\
Weights & $P_{B 1}$ & $P_{B 2}$ & $P_{B 3}$ \\
& $P_{C 1}$ & $P_{C 2}$ & $P_{C 3}$ \\
$W_{1}$ & $W_{2}$ & $W_{3}$
\end{tabular}

FIGURE 2.2. Matrix Structure 
There are two traditional methods of selecting a preferred alternative from this decision information.

1. Sequential Elimination. Here the decision maker performs qualitative tradeoffs in $h$ is preference of attribute performances. Preferences are established in a pairwise manner.

2. Threshold Levels. This method is commonly used in conjunction with sequential elimination. Specific attribute performance levels are determined as minimally acceptable. This reduces the consideration of alternatives to a reasonable number that can be treated sequentially.

The function of the matrix method is to provide a structure that presents relevant information in a concise, easy to interpret manner. The structure assures that estimates of performance will be made for each attribute on each alternative. Gaps in information are readily identified.

Generally the list of attributes and their applicability is determined without regard to value independence. As the process of analys is evolves, attributes may be aggregated in an implicit fashion. Here the first difficulty surfaces if the measures on the attributes are in different units. Second, if dependent attributes cannot be combined the possibility of double counting remains.

As discussed previously the problem of valuation is a key factor in the decision process. Matrix methods are flexible in the type of valuation measurements that can be used. Attributes can be measured in any scale or subjective descriptors can be used. The aggregation of the attribute measures in the matrix (setting of preferences) is compounded by a mixed set of measures. The cost-benefit and utility approach attempt to resolve this problem.

Principal advantages of the matrix approach are in its structure and its allowing different scales for different measures. Disadvantages include limited consideration of uncertainty, the problem of mixed valuation measures, and the difficulty of setting preferences.

Cost-Benefit - This approach resolves the valuation problem by translating the attribute performances into dollar quantities. Cost-benefit analysis 
is the most commonly used (and misused) formal method in government decision making. Numerous examples are available in the literature.

The advantages of cost-benefit analysis are twofold. First, the basis of cost-benefit analysis and its common metric, dollars, is familiar to both expert and layman. More importantly, data and methods for converting attribute performances to dollars are available in many instances.

In cost-benefit analysis positive performances are viewed as benefits and unfavorable performances are the costs. The common metric allows aggregation of outcomes (objective function) as either net benefits or a benefit-to-cost ratio.

A number of approaches are available for valuing performances in dollars. For many attributes market prices provide this information. When outcomes are not readily quantifiable in this manner the metrics must be inferred from behavior resulting from people's value systems. Thus, the gathering of measurements of attribute performance may become a difficult problem in application of this method. Several approaches include the following.

- Private market proxies - identifies the changes in the private market from responses to the nonquantifiable attribute consequence.

- Alternative cost approach - estimates the differences in what the consumer pays to maintain his current state in response to the consequence.

- Willingness to accept compensation - identifies the amount an individual will accept to experience the consequence.

- Willingness to pay approach - identifies the amount an individual will pay to avoid the consequence.

- Inquiry/lotteries - measures perceived values in bidding games.

There are several difficulties in using cost-benefit analysis. Social objectives such as equity cannot easily be quantified. Benefits do not always go to people who must bear the costs. Preferences in dollars are not measurable in all value systems. Similarly, societal and indivual values are always 
different. Operational difficulties and data definition extract a high price on the analysis. However, it is possible to gain measures on most attributes and set objective functions that indicate the relative preferences of either the decision maker or the public.

Multi-Attribute Utility Methods - These approaches are very similar to cost-benefit methods conceptually and theoretically. Here we focus on the differences.

The most obvious distinction between multi-attribute methods and costbenefit is the units in which the values of outcomes or consequences are ultimately measured. Multi-attribute methods determine these values in units called "utils." Thus, in multi-attribute utility analysis, the estimation of value is not an intermediate step to the derivation of total value for each alternative. Rather, the util measures of value are directly manipulated to arrive at a recommendation of one of the alternatives.

Although cost-benefit and this approach are conceptually similar, there has been significant difference between the two approaches in application. The first of these practical differences involves the method of utility or value estimation. Multi-attribute methods rely more heavily on direct inquiry to set values. Other differences include: 1) how values are estimated, 2) incorporation of uncertainty, and 3) intertemporal comparison.

To measure consequences in utils, direct inquiry methods are commonly used. The direct inquiry method selected depends partly on the approach used to incorporate uncertainty as risks. If the effects of uncertainty are considered negligible or if one is willing to use expected values in the analysis then either the paired comparison or direct scaling method may be used. If one is not willing to make these assumptions then lottery methods are selected.

- paired comparisons - An interview approach that assesses values by pairwise comparison of the desirability of attributes.

- direct scaling - Util values on each alternative are established independently. This is difficult in practice since people commonly set scales by comparative approaches. 
- lottery - When uncertainty is present, this method is one approach to characterize a measure of uncertainty. People are asked to assign values to uncertain outcomes.

Once the outcomes and measures for each al ternative have been determined, it is necessary to select a preferred alternative. In both cost-benefit and multi-attribute methods the selection is simplified and formalized by a consistent set of measures - either utils or dollars.

Decision Trees - These are formal structures used to depict and assess the uncertainty and temporal aspects of a decision process. Some decisions can be broken down into a sequence of several supplementary decisions.

The decision tree consists of a tree-like structure of "stages" where each stage consists of a decision alternative. At each stage, the decision maker can select one of several alternative actions. To capture uncertainty, a second type of stage called a "chance node" is used. Here, the uncertain outcomes resulting from a decision are depicted.

The first step in using a decision tree analysis is to graph the problem as a series of decision and chance nodes occurring sequentially over time. This is shown in Figure 2.3. In the figure, a square node represents a decision node and a circle represents a chance node. The two branches emanating from the initial decision represent the first of a possible sequence of decisions. In the example, there are two decisions; first, whether to start or delay, and second, if the initial decision was to delay, to either start later or to cancel. At each start decision there are two outcomes: success or failure. There is no uncertainty associated with the delay or cancel decisions.

In the figure there are three alternatives: 1) start, 2) delay then start, and 3) delay then cancel. These alternatives are represented by a path through the graph. As with other decision methods, each alternative is assessed with respect to its performance on a set of attributes, which include possible outcomes for cases of uncertainty. 


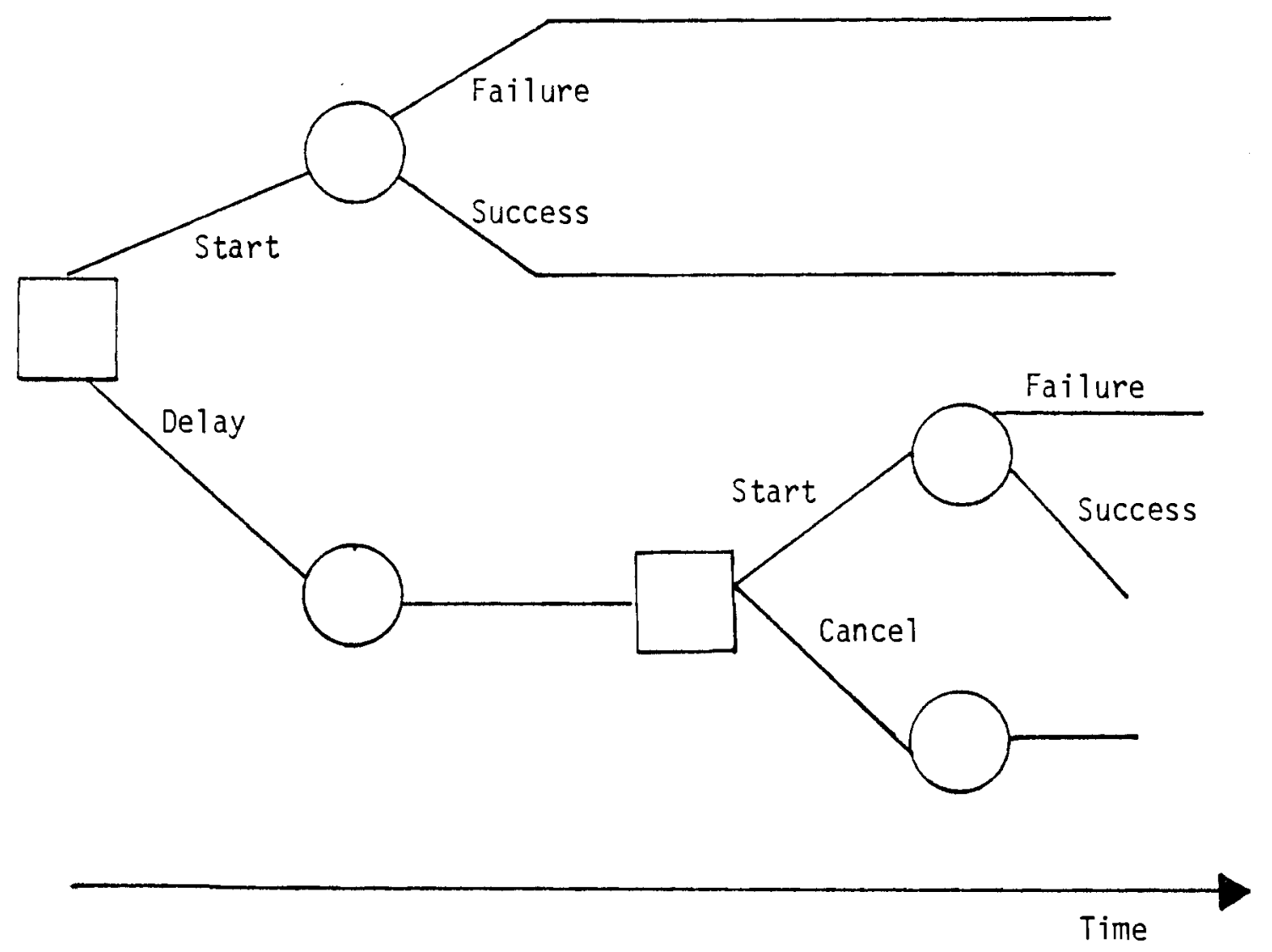

FIGURE 2.3. Example Decision Tree

The decision tree approach is particularly useful in breaking down complex decisions into a series of parts. These parts, or subdecisions, can then be individually assessed and combined as alternatives. The selection of attributes and the objective function for the decision is made in a manner similar to the other formal methods.

This chapter has introduced and discussed the key elements of the decision problem and the approaches to its resolution. The principal benefit of a formal method is in its structure, which provides a decision maker with a display of all the necessary information.

The key determination is the selection of an approach that suits the particular problem. This is determined by the information that is available about the problem. In effect, the selection problem may be likened to a 
decision problem itself. The next chapter discusses the selection of a decision method that accounts for the form and content of the information, how to value it, and how to treat its associated uncertainty. 


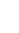




\subsection{SELECTING A FORMAL METHOD}

This chapter deals with the decision to use a formal decision method and its specifications. This decision is not in itself clearcut or readily obvious. As with most decision processes the design or selection of a suitable formal approach requires the making of tradeoffs based on the available information.

The decision to use a formal decision analysis method for a particular decision problem should never be one of a simple yes or no. The question should be one of degree of formality.

At the onset, the structure afforded any formal method provides documentation of the various considerations. This provides evidence and opportunity for all groups affected by the ultimate decision to have an effect on the process.

As the process evolves, the problem of information takes over in determining the appropriate degree of formality. The form and content of the available information, the difficulty in acquiring further information, its value, and the significance of the decision are all factors that must be considered.

There is no one "best" approach for making decisions. However, there is a "scientific method" for going about the process. This structure and process affords many advantages for decision making and is becoming increasingly necessary in order to account for all the information that must be considered for complex decisions.

Here we structure the questions one must ask and the intermediate decisions one must make. Deciding on the applicability of a formal method represents a decision under uncertainty. Although the discussion is organized along the lines of a formal method, a specific method (such as cost-benefit or utility analysis) is not used to depict the selection process. In practice, this decision process is nested in the decription of the problem and information used to make tradeoffs. 


\subsection{SETTING OBJECTIVES}

Every decision process must begin with the definition of an overall goal. To some extent this is specified a priori for public decisions. For most public decisions this goal is to select an alternative that will lead to the greatest possible increase in social welfare.

For the various regulatory agencies, Congress has provided mandates and some general guidance on objectives. Congress rarely requires the application of particular decision making methods or techniques. Similarly the judicial branch, via its interpretations and determinations, serves to delimit the breadth and scope of the goals of regulatory agencies' decisions. It remains in the hands of the agency or the individual decision maker to determine the depth of the analysis for the decision.

4 General goals related to regulatory mandates and social values are next interpreted as general goals or objectives of the specific organization. For example, Carlson (1978) lists general goals that he refers to as research categories:

- improve safety

- improve regulatory process effectiveness

- improve regulatory process efficiency.

This set is descriptive of the general set of reasons (goals) one may define in consideration of a formal decision methodology. For the first goal, improve safety, the efficacy of an improved method is decision problem specific. The other two, improve effectiveness and improve efficiency, are generic to the decision making process.

The selection of a formal method must be made on the context of a decision problem or class of problems. Regulatory decisions may be classified as being related to policy, procedures, or of technical nature. For example, the determination of regulatory needs or required regulatory research are representative of decision problems of policy. Procedural decisions such as those necessary for licensing are based on the determination of compliance with regulatory requirements. Technical decisions set standards or requirements that serve the general policy. 
The potential for the application of an improved decision methodology must be bounded as to the type of decision problem it is meant to address. For most applications this will be clear.

The second part of goal setting is to identify those people who are affected by the decision and whose values are important considerations. At a global level, these people represent the view of individuals, groups or society at large on the decision at hand.

To determine the analysis boundary, subobjectives should be selected that contribute to the overall goal and include the appropriate segment of society. Subobjectives begin the transition to the decision problem solution. A hierarchy of subgoals should be identified, each supporting the objective either wholly or in some aspect. This determination ultimately allows measurement or analytical treatment. Figure 3.1 simply depicts the process of setting objectives and developing a set of decision criteria. In Chapter 2 the final set of subobjectives were referred to as criteria.

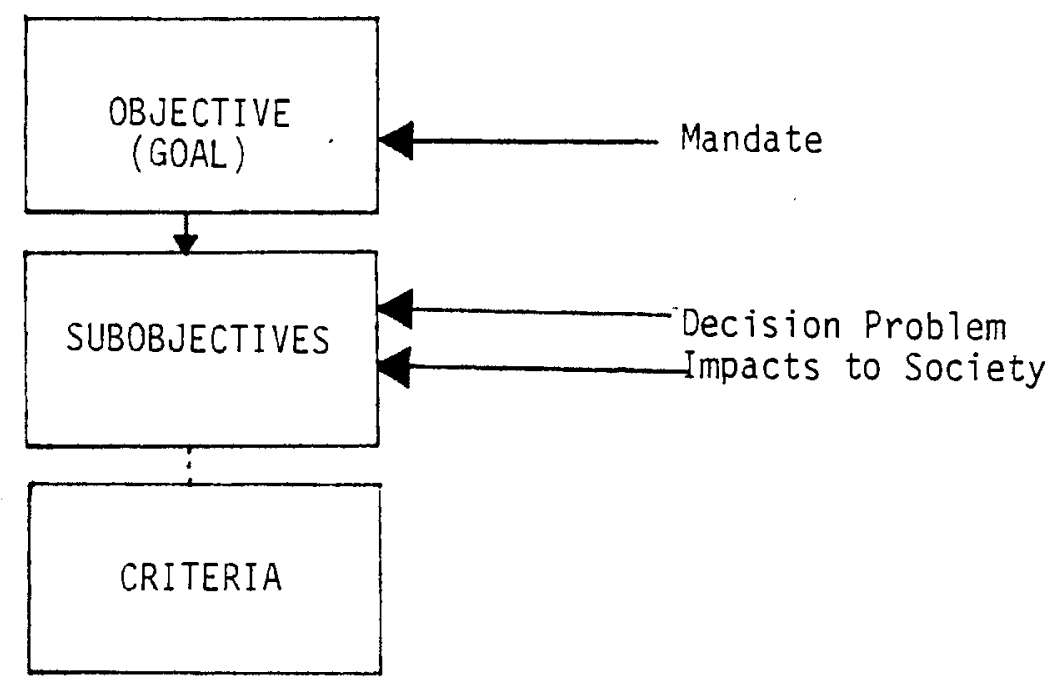

FIGURE 3.1. Setting Objectives 
To summarize, goal setting has three important aspects. They are as follows.

- A singular objective statement must be determined which bounds the decision problem. The decision problem may be classified within the general scope of decisions regularly considered.

- The relevant persons affected by the decision or whose values will influence the decision must be identified and categorized.

- Based on the objective and those persons whose values are relevent, a hierarchy of decision criteria must be developed. Pruning this hierarchy is a judgmental decision based on estimates about the importance of the decision or having an exhaustive set of criteria. Questions about the appropriateness of a formal method that can be asked after objectives are set include the following.

- Is the decision such that some subobjectives, if satisfied, appear conflicting?

- Are there a large number of subobjectives at each level (breadth) or many levels (depth)?

- Is the decision important?

\subsection{DETERMINING ALTERNATIVES}

Determining good alternatives is a difficult conceptual step in the decision process. The set of alternatives, however, is of ten constrained by $a$ number of factors that represent additional boundaries to the decision. Identifying these boundaries often delimits the set of available alternatives.

The first boundary for the alternatives is given by the subobjectives of the decision problem. The alternatives must be designed as means for achieving the objectives of the problem. For this purpose, each must "cover" the lowest level subobjectives. The "do nothing" or status quo alternative should be included as a basis for comparison.

The mechanisms available for implementing a decision provide the second boundary. For public decisions, the authority provided by the regulatory 
mandate, the available vehicles and legal interpretations of authority all bound the possible alternatives. For the NRC, the highest level mechanism is regulations. Other mechanisms include regulatory guides, research letters, disseminating information, and conducting research programs. To a large extent, Congress has provided the NRC broad discretion in fulfilling its mandates.

For decisions that incorporate technology, its feasibility provides bounds on potential alternatives. Standards cannot be set beyond the limits of feasibility, however, certain decisions might require establishment of those limits.

A fourth boundary, akin to the available mechanisms, is provided by necessary procedures that must be followed in effecting an alternative. For example, provisions for judicial review of agency decisions provide controls on its discretion. Legal requirements for advisory boards, public hearings, comment reviews, or impact statements are all factors in designing alternatives.

In determining alternatives, the range of consideration is constrained by the following factors.

- selecting alternatives that serve the lowest level subobjectives

- considering the mechanisms available for implementing decisions

- technical feasibility

- the necessary procedures that must be followed.

These factors are depicted in Figure 3.2 as influencing the selection of alternatives.

Several considerations should not be included when defining alternatives. Any considerations which prejudge alternatives may stifle the identification of an optimal solution before it is given a fair hearing. The selection of alternatives should:

- not be a decision process unto itself where preferences and value judgments are required

- not exclude outside input from people with possibly different perspectives 


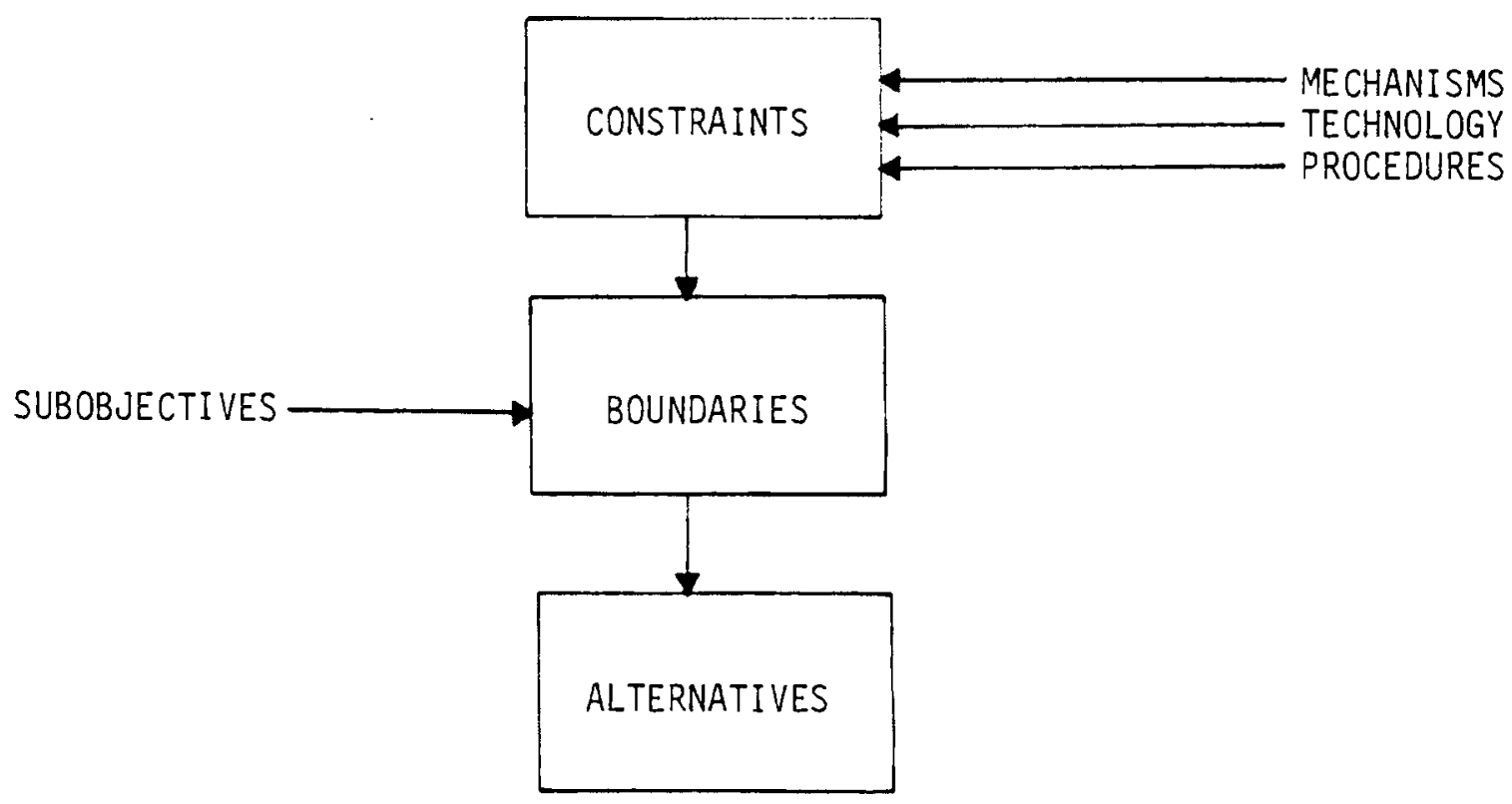

FIGURE 3.2. Determining Alternatives

- not be closed (e.g., disallowing new alternatives as the decision process evolves).

Questions relative to the alternatives are as follows.

- Are there a large number of alternatives?

- Are the alternatives bounded differently in terms of implementing the decision or assessing each's impact?

- Will a determination of technical feasibility be required?

- Are there a large number of boundaries or constraints on each alternative?

- Are any of the alternatives relatively indistinguishable in cursory review in terms of desirability (i.e., is there no obvious decision)?

To this point, the analysis of the decision problem will evolve similarly for any decision. The process of setting objectives and determining alternatives may be structured to the extent necessary to depict the decision being considered. Here, the necessary information about the objectives and the bounds on possible solutions must be determined. 


\subsection{SELECTING ATTRIBUTES}

Having set objectives and determined the alternatives, one can decide what factors are most important in achieving the objectives. These important consequences must be measured.

The selection of attributes is sometimes difficult. At first, qualitative descriptions of how an objective (subobjective) may be met are made.

Because objectives and subobjectives rarely are directly measurable, great care should be taken to assure that the objectives are accurately described. Attributes must be defined in a manner that allows measurement of each alternative on each subobjective.

For objectives that do not have readily quantifiable attributes, proxy attributes may be defined. An example proxy attribute is biological oxygen demand as an indicator of water quality. The value of the proxy attribute as an indicator is established later. The problem of quantification can also be resolved by the development of an index which combines several measures of performance on an objective.

As indicated previously, attributes must be estimable and comprehensive. Additionally, it is desirable that they be value independent and of minimum number. Comprehensive means that each subobjective be covered by an attribute; minimum size means that multiple attributes on a given objective should be kept to a minimum.

One of our key issues, describing uncertainty, is associated with the definition of attributes. Although there are other possible ways to characterize uncertainty such as fuzzy set theory, probabilistic approaches are the norm. Uncertainty is incorporated into formal decision methods as either discrete probability events or as a continuous probability distribution. The selection of discrete or continuous descriptions of uncertainty is dependent on the type of outcomes considered. Binary outcomes such as yes or no steps would be described discretely. Continuous outcomes such as radiation exposure are described over a spectrum of outcomes. 
Once the necessary information about uncertain outcomes is probabilistically described it is referred to as uncertainty. Other statistical attributes such as expected value (mean), most likely outcome (mode), and confidence interval estimates are also commoniy used. There are many difficulties associated with the measurement or estimation of uncertainty. Chapter 4 discusses this in more detail.

In sum, the selection of attributes involves several considerations:

- Attributes should first be described qualitatively, allowing measurement of each important outcome and accounting for people who may be impacted by each outcome.

- Attributes should be selected in deference to a given formal method that may dictate specific methods of valuation.

- In translating the qualitative attribute descriptions into quantitative measures, each subobjective should have an associated attribute.

- Comprehensiveness and estimability should be considered in the selection process.

The selection of attributes and their description as quantitative measures is illustrated in Figure 3.3.

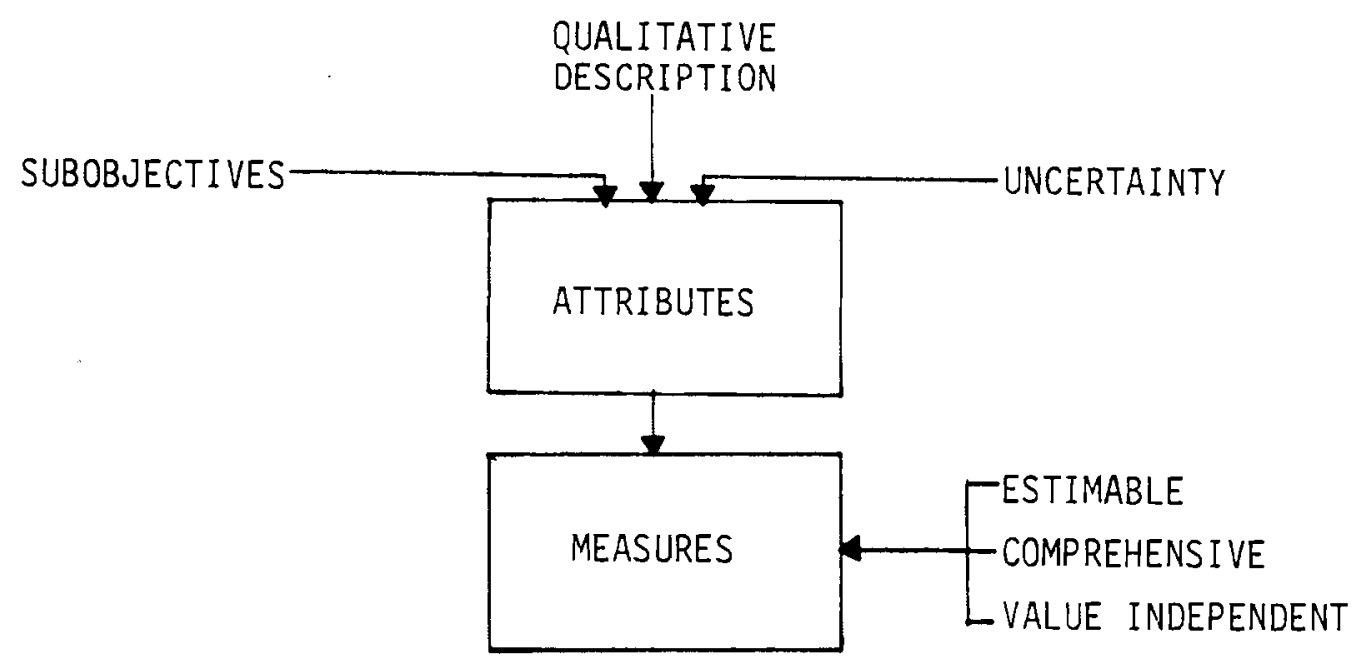

FIGURE 3.3. Select Attributes 
Because the selected attributes have the potential of affecting the outcome of the analysis, the iterative nature of the decision process is emphasized. The selection of an objective function and its associated valuation approach account for attributes in different ways. Additionally, dependent attributes are not always identified until a valuation or sample analysis is performed. Objectives may not even have quantifiable attributes, in such cases subobjective attributes may be developed.

Again, questions indicating the applicability of formal methods can be asked in the selection of attributes.

- Are there multiple attributes on each objective?

- Do the attribute measures or indices have different scales, or are different combined measures used as indices?

- Are proxy or subjective attributes necessary to assure measures on all the objectives?

- Is the measurement of uncertainty necessary in any of the attributes?

- Are there possible dependencies between attributes indicating possible double counting?

As before, complexity is the driving factor which points to the need for a structured, formal method. For the attributes, their metrics may indicate a preferred formal method. The use of indices or subjective measures may indicate a matrix approach. A preponderance of economic metrics may lead to a cost-benefit approach; multiple mixed metrics a utility (multi-attribute) approach.

\subsection{SYNTHESIZING AN OBJECTIVE FUNCTION}

Reaching this stage of the analys is requires a choice between formal methods. Each formal method strongly influences which measures of desirability for attribute performances (preferences) are used. The selection of a formal method depends on its need, the available information, the objectives and the time and resources available. 
Objective functions provide a basis for aggregating the attribute measures into a performance score for the alternatives. They provide a form for incorporating each of the attribute performances of an alternative in a consistent manner. As such, synthes is of an objective function requires viewing the selected attributes in a holistic fashion.

Five aspects of the attributes should be considered for the synthesis of an objective function. Each is important in establishing tradeoffs of desirability between attributes. Here, the analyst or decision maker forms the basis for setting preferences between attribute performance.

The first comparison of the attributes is on the basis of the relative scales of their metrics. A nominal scale is a simple grouping of measures into classes. Ordinal scales rank attributes, of ten subjectively using less than or greater than relationships. Interval scales preserve distance between measures. Ratio or cardinal scales allow zero and negative mesures.

Nominal or ordinal scales have a subjective basis, are difficult to combine with other metrics, and are indicative of matrix approaches. Interval scales (e.g., rankings from one to ten) provide a numeraire that should only be combined in an additive fashion requiring independence. Interval scales are suitable for probabilistic descriptions of uncertainty. Cardinal or ratio scales are easiest to aggregate when comparing positive and negative preferences.

The second aspect compares the change in preference with incremental changes in attribute measures. For a linear relation an increase or decrease in attribute measures implies a directly proportional change in preference. When the desirability of an attribute's performance is a function of that performance, the relation may be nonlinear. Nonlinear attribute performances are difficult to combine.

The attributes should also be reviewed for value dependence. If desirability of an attribute's performance is related to the performance of some other attributes, then it may be double counted.

The fourth aspect for which the attributes must be reviewed is uncertainty. If the preference on outcomes is not on the same scale as the 
outcomes, then a functional relation must also be determined. This is often complicated and difficult to communicate. For this reason singular statistical measures are often carried through the analysis (e.g., expected values) if uncertainty exists. Sensitivity analysis is used to test the extreme outcomes.

As with the other steps of the decision analysis process, the preferred objective function is determined iteratively. A review of the attributes with respect to the above five aspects does, however, begin to indicate specific formal methods:

- If many of the attributes have a subjective basis, use indices, or have nominal or ordinal scales, a matrix approach will provide the simplest objective function. If the attributes use ratios or cardinal scales, objective functions having a common metric may be appropriate.

- If the preference or desirability of outcomes on attribute measures are nonlinear, then a nonlinear objective function is indiated. A utility function is the most common approach for assessing these nonlinearities.

- Dependence among attribute measures is also indicative of the need for a nonlinear objective function.

- From a cost-benefit perspective, consequences may be accrued differently to different aspects of society. Further, any result where some people gain and others lose could be transformed into a common measure of desirability if those who gain were able to use these gains to compensate others for their losses.

- The description of uncertainty and its valuation are interdependent. In assessing uncertainty the resulting objective function is often nonlinear.

- The presence of multiple attributes does not necessarily indicate a utility or multi-attribute approach. If attributes exist that are not readily quantified, then determination of utility functions or 
dollar measures will be equally difficult. The decision about the appropriate formal method depends upon how we 11 the attributes are defined quantitatively.

The selection of a preferred decision method requires a review of the attributes and knowledge of the available methodologies. The first step is to decide if the attributes are to be preserved in the objective function; indicating either a matrix approach or the desire for a common metric. If a common metric is desired, then the choice between dollars and utils must be made. This must be based on whether one believes that all the important consequences of each alternative can be most accurately valued in one term or the other. Figure 3.4 shows the synthes is of an objective function.

Questions one should ask in synthesizing an objective function are as follows.

- Are the important attributes based on an index or other subjective measures?

- Are negative aspects captured in the attributes by either ratio or cardinal scales?

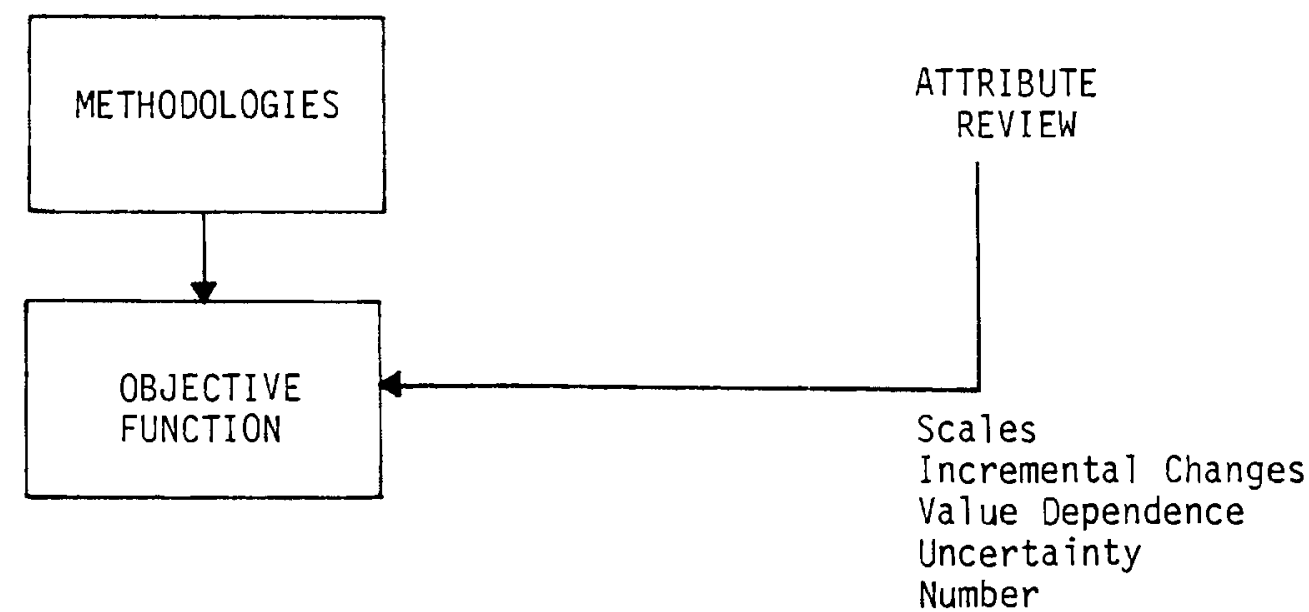

FIGURE 3.4. Synthesizing an Objective Function 
- Are preferences nonlinear with incremental changes in attribute performance measures?

- Is uncertainty a factor?

- Are attributes independent and linear, allowing an aggregate objective function that is additive?

- Is it important to preserve attributes in their original form, or will a common metric capture the process?

In asking the above questions, the possibility of a hybrid approach of ten occurs. This is of ten the case in practice. For example, attributes that are well captured in dollars may be aggregated in an objective function. This result is then combined as part of a matrix or utility function approach. This two-phase synthesis of an objective function, of course, involves making tradeoffs in dollar terms with other attributes for a common measure of value. In practice there are certain attributes, particularly associated with risk, that are difficult to value in dollars.

\subsection{VALUING PREFERENCES}

Setting values on attribute performances is the most technically difficult part of the decision process. In effect, the key contribution of formal methods is to quantify this of ten subjective process. In Chapter 2 some of the common methods of valuation were briefly discussed. Here we focus on the aspects of problems associated with valuation. These can be separated into those associated with the decision problem, people's perspectives, and those associated with approaches to estimating values.

Issues associated with the decision problem description have been discussed in the previous sections of this chapter. The possible effect of preferences and value systems must be considered in setting objectives, determining alternatives and selecting attributes.

The analyst or decision maker must be sensitive to problems of valuation (perspectives) in characterizing the decision process. This requires a sensitivity to the impact of consequences in terms of society's or group's value 
systems and an awareness of the techniques and problems associated with gleaning these values. Issues of importance with respect to possible value systems include the following.

- The value of some outcome may depend on the extent of associated outcomes and on the present environment of the persons whose values are deemed to be a factor.

- Values may change between the time of their measurement and the time of implementation of a decision. Additionally, outcomes may occur over time and their temporal effects must be integrated.

- Different alternatives may affect different groups of society. The questions of whose values should be used and what weights to give each person or group when combining values remain unresolved.

- People often have difficulty understanding descriptions of uncertainty and with different ratings between uncertain outcomes.

The problems associated with estimating preferences and accounting for value systems are shown in Figure 3.5 .

Issues associated with estimating values are interrelated with the above preference issues. They include the following.

- It is important but also difficult to measure the value of alternatives which impact groups in different ways. The most difficult case is when value systems are in conflict.

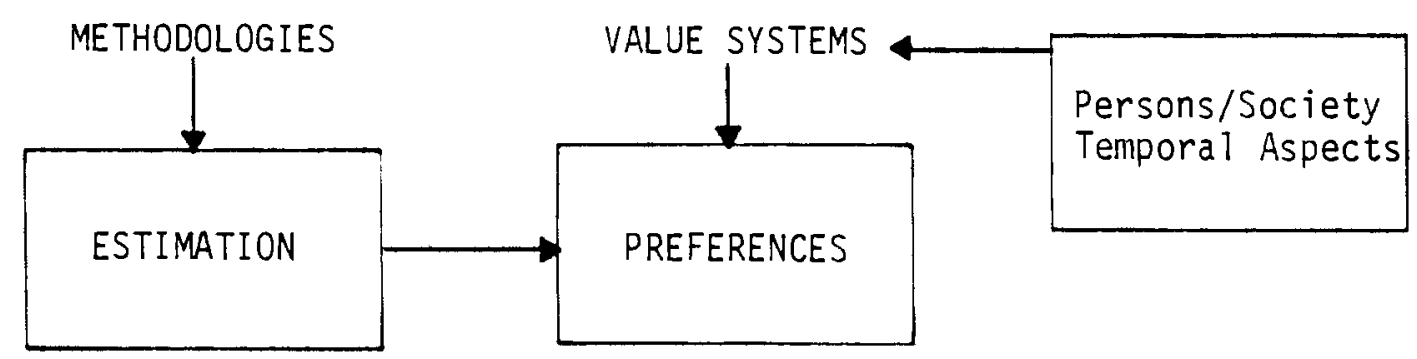

FIGURE 3.5. Valuing Preferences 
- The quality of survey data may be questionable for a variety of reasons. Valuation techniques have many limitations.

In Chapter 2 several of the approaches for valuing preferences were listed in the discussions of cost-benefit and multi-attribute utility methods. These can be separated into market and direct approaches. Market approaches attempt to determine monetary values associated with preferences. Direct methods usually result in utility functions. In both cases, sampling polls, surveys, and other questioning methods are commonly used to determine value systems.

For market approaches, market equilibrium is assumed. Nonmarket effects such as equity, flexibility, quality, growth, and reversibility of trends remain external to the analysis. Free market assumptions are necessary to the analysis and transaction costs are not often incorporated.

For direct valuation approaches the common metric is utility which is difficult for people to relate to. Similarly, the utilities of different groups are difficult to aggregate.

In both valuation approaches there are common difficulties associated with sociological sampling. Preferences and behavior are often inconsistent. Also, people may exaggerate preferences in order to mislead decision makers. In each approach, the wording, sequence, and type of questions asked can introduce possible biases. There are, however, several differences in application that exist between cost-benefit and multi-attribute utility analysis. The focus of multi-attribute approaches has been on the inquiry methods of valuation. However, the use of inquiry methods (e.g., lottery games for which private markets do not exist) is increasing in cost-benefit applications.

In sumary, the five elements of the decision process shown in Figures 3.1 through 3.5 are combined in Figure 3.6. As shown, objectives are first set and described as criteria. Attributes are then designed to measure performance of alternatives on these criteria. Attributes and criteria are shown as equivalent in the figure. The attributes and knowledge of available 
methods are used to synthesize an objective function. Alternatives are deve1oped independently and then assessed for the decision.

The decision process, as simply shown in Figure 3.6, is necessarily iterative. The availability of information at each step will influence all aspects of the process. There is no one "best" approach or method. However, the steps and the various considerations, one must make as the process evolves are common to all formal methods.

\section{SETTING OBJECTIVES}

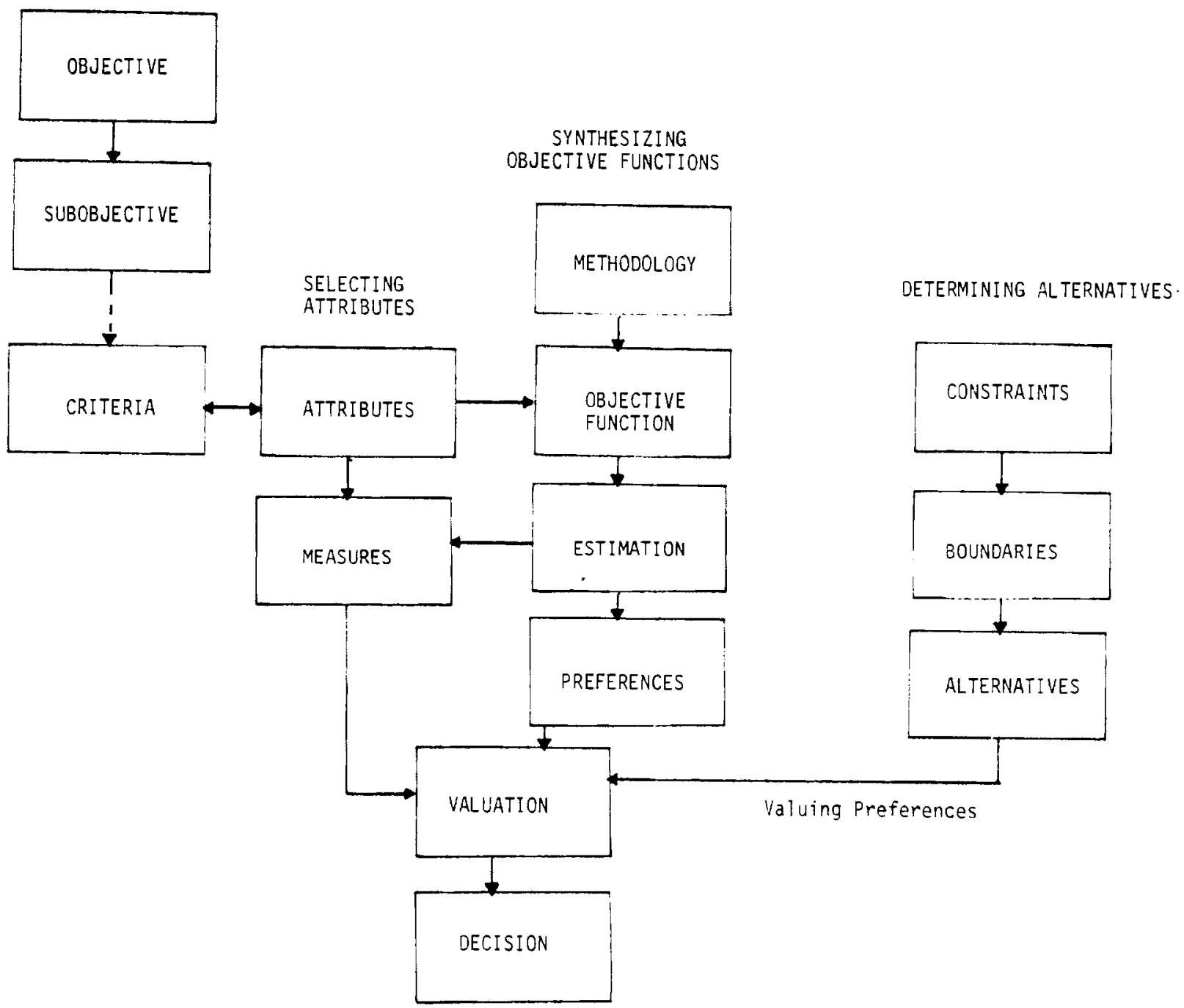

FIGURE 3.6. Decision Process 


\subsection{THE MEASUREMENT OF RISK}

The concepts of reactor safety and reactor risk are usually synonymous to decision makers. Of the two terms, risk $(R)$ is the more specific implying both a frequency of events and the consequence of these events. Fundamentally, risk is characterized by a probability density function, $p(c)$, describing the likelihood of a given magnitude of consequence per unit/time. Often risk is represented by the expectation value of the consequence:

$$
R=\int c p(c) d c
$$

or by the complementary cumulative distribution function:

$$
P(c)=\int_{c}^{\infty} p(c) d c
$$

which describes the likelihood $P(c)$ of an event in which the consequences are greater than or equal to $c$. Although reactor safety or reactor risk is normally foremost in the minds of regulators of nuclear power, the measurement of risk has seldom been treated in significant depth in achieving a regulatory decision. This section reviews the history of studies involving the measurement of risk, identifies the baseline data available for using risk analys is in decision-making, and describes methods for performing risk analysis.

\subsection{SURVEY OF THE USE OF RISK MEASURES IN REGULATORY DECISION MAKING}

The Design Basis Accident approach to the design and licensing of nuclear power plants does not involve the explicit consideration of risk. In this approach, the plant is designed such that the consequences of a set of credible accidents will be within acceptable limits. Selection of the design basis accidents is made using engineering judgment. Prior to the issuance of the report on the Reactor Safety Study in 1975 Rasmussen (1975), little use 
was made of risk analysis in arriving at licensing decisions. Some judgmental consideration was given to the probabilities of events to determine whether or not they should be considered as design basis events. For example, the need to consider airplane crashes in the design of a shield building for the containment dome was based upon the likelihood of airplane impact, which in turn depended on the proximity to airfields. If the probability of impact was found to be less than $10^{-6}$ to $10^{-7} / \mathrm{yr}$, it was not considered necessary to design for the event.

The largest effort undertaken by the Nuclear Regulatory Commission was to base a regulatory decision on risk analysis is the study on Anticipated Transients Without Scram (ATWS) (NRC 1978a). The value-impact analysis performed for the ATWS study went to considerable effort to assure that all important values and impacts had been considered. Risk to human health was treated on the basis of person-rem exposure and converted to an equivalent dollars value based on $\$ 1000$ per person-rem (approximately $\$ 5$ million per fatality). The estimate of risk to the public relied heavily on the analyses in the Reactor Safety Study.

In 1977, Congress expanded the charter of the Nuclear Regulatory Commission to include research on concepts to improve the safety of reactors. In April of 1978, a "Plan for Research to Improve the Safety of Light-Water Nuclear Power Plants" (NRC 1978b) was issued. In the development of the plan, four attributes were used to evaluate the potential merits of each concept and to prioritize the concepts for future research. These attributes were: risk reduction potential, generic applicability, cost of implementation and breadth of support. Each of the attributes was treated in a semi-quantitative fashion. Risk reduction potential was characterized as high, medium, or low. No analyses were performed specifically for this evaluation but heavy reliance was made or insights obtained from the Reactor Safety Study.

Measures of risk have been used in other studies including an evaluation of the merits of alternative approaches to containment design (Carlson and Hickman, 1978) and in the ranking of the importance of generic unresolved 
safety issues ("Reporting the Progress of Resolution of 'Unresolved Safety Issue' in the NRC Annual Report" 1978). In all cases, however, the measure of risk used has been highly qualitative.

\subsection{AVAILABLE BASELINE DATA}

There are currently about 70 reactors operating in the United States and more are under construction. Depending upon the type of decision under consideration, it could be necessary to evaluate the impact of the decision on the risk arising from each of these reactors. In order to make such an analysis tractable, however, it is necessary to characterize these reactors by as few generic models as possible. In the Reactor Safety Study, a population of 100 reactors was characterized by just two models, the Surry PWR and the Peachbottom 2 BWR. Unfortunately, reactor designs vary considerably. Each of the four LWR vendors has a series of designs for the nuclear steam supply system. Each steam supply system is then mated with a balance of plants designed by the architect engineer and is located on its own site. At the finest level of detail each plant is indeed unique. For a given decision, however, only certain features of the plant will be important, and it will be possible to group plants according to these features.

The depth of analysis of risk undertaken in the Reactor Safety Study for the Surry and Peachbottom $2 \mathrm{plants}$ far exceeds that for any other plant designs. These plants are a 3-loop Westinghouse design with subatmospheric containment and a General Electric design with Mark I containment, respectively. The German Risk Study (1979) is the only other comparable investigation, but is of very little value in better understanding the risk from American designs.

In the Reactor Safety Study Methodology Applications Program (Asselin et al. 1978), four other LWR designs are being analyzed: a Westinghouse 4-loop design with ice-condenser containment; a Babcock and Wilcox design; a Combustion Engineering design; and a General Electric design with Mark III containment. The level of risk analysis performed for these plants is not of comparable depth to the Reactor Safety Study but is believed to be adequate to 
identify the dominant accident sequences. A new program, Interim Reliability Evaluation Program (Murley 1980), is being undertaken by the NRC which could add appreciably to the data on reactor risk. In this program, it is intended to perform systems analyses for a 11 operating plants to identify system faults or weaknesses that could be major contributors to risk.

\subsection{METHODS OF RISK ANALYSIS}

As the most complete risk analysis that has been undertaken, the Reactor Safety Study serves as the model for methods of risk analysis. In this approach, accident sequences are identified by the use of event trees. The trees begin with an assumed inititating event and branch out depending on the success or failure of important engineered safety features. The ends of the branches correspond to specific accident sequences. Probabilities for the branch points can then be propagated through the trees. The consequences can be calculated using deterministic models to describe the course of the accident, dispersion of radioactivity in the environment and the effect of radiation exposure on human health. The probabilities and consequences opf sequences are then combined to produce risk. A number of variations and extensions to the Reactor Safety Study methodology exist. Variations to fault tree analysis, such as the Digraph method (Powers, Thompkins, and Lapp 1975), have been developed which attempt to make the method simpler or the results less sensitive to the analyst making the calculations. Lofgren et al. (1980) have examined methods of extending the binomial nature of event trees to the use of density functions describing a continuum of system states. Major innovations and improvements in risk assessment techniques can probably be expected for a number of years.

Clearly, if it were necessary to perform the equivalent of the Reactor Safety Study to form the basis for each regulatory decision, there would not be many decisions made. A full risk analysis is too costly and too time consuming. In the Reactor Safety Study Methodology Applications Program, a more superficial approach to risk analysis has been used to estimate the risk without the necessity for performing detailed fault tree analyses. Similarly in the Interim Reliability Evaluation Program, it is not intended to perform 
consequence analyses for each sequence. Instead, the consequences will be estimated based upon experience in the analys is of similar sequences for similar plant designs.

Although the decision maker might like to have a simple generic method for estimating differences in risk associated with each decision alternative, it is unlikely that a method of this type can be developed which is independent of the application. It will, therefore, be necessary for the decision maker to gain experience in the use of risk analysis techniques or for the decision maker to have access to staff with these capabilities.

\subsection{BIBLIOGRAPHY}

The articles included in the bibliography provide a good introduction to risk benefit analyses for nuclear power plants. 
. 


\subsection{THE VALUATION OF RISK IN DECISION MAKING}

This section discusses the valuing of risk as a parameter in decision making. In Table 5.1 the risk from nuclear power plant accidents is subdivided into three types of criteria: 1) Human Health Effects, 2) Property Damage, and 3) Aesthetics/Environment. The criteria are further broken down into attributes. Whereas the criteria must be described in general terms, the attributes are quantifiable. In performing a value-impact analysis, the attributes would be the values and impacts. In general, the attributes are measured on a relative or marginal basis since a decision is made from among alternatives. Thus, an improved safety system in a nuclear power plant could result in a reduction in risk of " $x$ " early fatalities per year, which would be a "value" of the system. The same system could also result in a reduction of "Y" dollars per year required for land decontamination. This could either represent a "value" or could be entered as a negative "impact." Since many of the impacts of safety systems can be conveniently measured in dollars (e.g., the cost of the system), decision makers frequently prefer to identify as impacts all of the attributes that are naturally measured in dollars. This reduces to some extent the problem of comparing apples and oranges when a variety of criteria is being considered.

\section{TABLE 5.1. Risk Values and Impacts}

\begin{tabular}{cllll}
\multirow{2}{*}{ Criteria } & Human Health Effects & Property Damage & Aesthetics/Environment \\
\cline { 2 - 3 } Attributes & Early Fatalities & Offsite Damage & Loss of Land Use \\
& Early Illness & Damage to the & Loss of Water Use \\
Delayed Fatalities & Facility & \\
& Delayed Illness & Cost of Replace- \\
& Genetic Defects & ment Power \\
& Life Shortening &
\end{tabular}

Weighting of attributes is an essential aspect of the use of risk in decision making. The magnitude of risk to the public estimated in risk studies, even using very pessimistic assumptions as in the review of the Reactor Safety Study by the Union of Concerned Scientists, is very small in 
comparison to other risks. Clearly, there are aspects of the risk from nuclear power plants that have special significance in the perception of the public. One of these aspects is the aversion of the public to multiple fatality accidents (catastrophes). The weighting of attributes according to criteria level is termed utility. The public's utility function for fatalities apparently increases rapidly with the number of fatalities. In order to aggregate attributes it is also necessary to determine their relative weights. This type of weighting is termed preference.

In this section of the report, each of the risk related attributes that could be used in decision making will be discussed. Some insights will also be provided into the difficult problem of weighting attributes.

\subsection{RISK RELATED ATTRIBUTES}

The following sections discuss some of the risk related attributes in common use.

\subsubsection{Human Health Effects}

\section{Early Fatalities}

Early fatalities following a reactor accident depend upon the dose received, whether the dose is internal or external, and the amount and type of medical care available. The three organs or organ systems whose failure produces most early fatalities are the lungs, bone marrow, and gastrointestinal tract. Although the absolute risk to the public from early fatalities is probably very smal1, this appears to be the greatest source of public concern about nuclear power plant accidents. Early fatalities would only be expected to result from meltdown accidents involving early failure of the containment to the environment, affecting people located within a few miles of the plant. If such an accident were to occur, however, the associated deaths would be observable and could be directly associated with the event. The level of exposure that would lead to death is comparatively we 11 known, although different groups in society (e.g., the elderly) are more or less sensitive to exposure. 


\section{Early Illness}

Early illnesses may occur when a person receives a substantial but nonlethal dose of ionizing radiation. These illnesses include vomiting, cataracts, growth retardation, temporary sterility, and impaired functioning of thyroid, lungs, and gastrointestinal tract. As for early fatalities, the consequences of the event would be readily observable and could be related directly to the accident. Although the affected individual would be expected to have an increased likelihood of later incidence of cancer, his physical health would otherwise be changed very little. The potential psychological impact on the individual is very difficult to assess, however.

\section{Delayed Fataltities}

From an objective viewpoint, delayed fatalities are probably the most significant potential heal th hazards from accidents in nuclear power plants. The results of the Reactor Safety Study (1978) and the German Risk Study (1979) both both indicate that the expected number of delayed fatalities from accidents is much greater than the number of early fatalities. However, latent cancer deaths in the exposed population could probably not be measured or related back to the causal event. Some of the principal types of cancer of concern are leukemia and cancers of the throid, lung, gastrointestinal tract, breast, and bone. The cancers would occur over a 20 to 30 year plateau period following a delay period of 10 to 20 years. Cancers resulting from radiation exposure are clinically indistinguishable from those caused by other carcinogenic agents. The increased likelihood of cancer is estimated using the calculated exposure to critical organs.

\section{Delayed Illness}

In addition to the increased likelihood of fatal cancers in the population there would, of course, be cancers that are operable or treatable with radiation or chemotherapy. These, too, would be ind istinguishable from the background incidence of cancer in the population. A high incidence of thyroid nodules would also be expected as the result of exposure to radioactive iodine. Most of these nodules would be benign and the majority of cancerous nodules would be operable. 


\section{Genetic Effects}

Genetic effects of exposure to radiation are measured in the offspring of the exposed population rather than in the population itself. They would be expected to occur over a number of generations. As for malignancies, the occurrence of genetic defects would be indistinguishable from the defects arising from other agents in the environment and would probably not be detectable in the exposed population.

\section{Life Shortening}

Life shortening is a single attribute which includes the effects of both early and delayed fatalities. In order to avoid double counting, life shortening should not be used simultaneously with early or delayed fatalities as an attribute. Analyses by Davis (1977) indicate that in a typical population, the degree of life shortening associated with latent fatalities is approximately $1 / 3$ that of immediate deaths.

\subsubsection{Property Damage}

\section{Offsite Damage}

The most immediate economic losses to the public in an accident involve damage to the property of private citizens in the vicinity of the plant. These losses include damage to crops, interdiction and destruction of milk, fish, and other food supplies, the cost of decontamination, loss of jobs, and the costs associated with relocation of people. Loss of land use or water use can also have economic impacts. Within specified limits, these losses would be covered by insurance.

\section{Damage to the Facility}

The cost of a large nuclear power plant is approximately one billion dollars. The current estimate for cleaning up the TMI-2 facility and bringing it back on line is approximately half that much. Thus, even for an accident that does not result in core meltdown, the cost of repair can be very high. Although the cost impact on the public is not immediate, inevitably, the public would pay the cost of repair or replacement. The cost would probably be spread over a larger base than the immediate service area through insurance. 


\section{Cost of Replacement Power}

The accident at TMI-2 has shown that the cost of replacement power can also be a significant economic impact. In the past this cost would not have been covered by insurance and would have been passed on to customers in the service area. An insurance pool is currently being formed to cover this type of loss.

\subsubsection{Aesthetics/Environment}

Loss of Land Use

Although a severe nuclear accident could result in the death of plants and animals in addition to humans, no significant sustained impact on ecosystems would be expected to result. It could, however, be necessary to prevent the use of significant areas of land for farming or habitation for many years. In addition to the economic impact of loss of land use described earlier, this loss could have a singificant aesthetic or psychological effect on the population, particularly for people forced to move from their homes or conmunities.

\section{Loss of Water Use}

As for loss of land use, isolation of a water body from public use would have more than economic impacts. For example, loss of recreational features of a water body could affect a large sector of the population.

\subsection{PROBLEMS WITH AND INSIGHTS INTO THE SELECTION AND WEIGHTING OF ATTRIBUTES}

This section provides the reader with an understanding of some of the complexities and pitfalls in the use of risk-related attributes in a decision process. A number of important questions will be addressed:

- What is the relative importance of risk attributes?

- What is the effect of timing of consequences?

- Who is at risk?

- How do uncertainties affect the use of risk in decision making?

It is not our intent to attempt to answer these questions in this report, but rather to provide insight into the scope of the associated problems. 


\subsubsection{What is the Relative Importance of the Risk Attributes?}

Using results from the Reactor Safety Study, societal risks from 100 power plants are presented in Table 5.2 according to six attributes. In the second column the values are adjusted for a single plant. The cost of a new plant $\left(\$ 1 \times 10^{9}\right)$ has been included under property damage to account approximately for cleanup and repair for each core meltdown accident. In addition, Delayed Fatalities, Delayed Illness, and Genetic Effects have been multiplied by an assumed plateau period of 30 years. (a) In Column 3 , weights are provided for the corss comparison of the attributes. These weights are merely chosen for the purpose of illustrative example. there is no single correct set of weights that can be determined. Weighting of attributes is dependent on the value judgments of the decision maker. The bases for the specific weights chosen in this example are as follows.

TABLE 5.2. Comparison of the Importance of Weighted Attributes

\begin{tabular}{|c|c|c|c|c|}
\hline Attribute & $\begin{array}{c}\text { Societal (a) } \\
\text { Risk } \\
(\# / 100 \text { plant yr) } \\
\end{array}$ & $\begin{array}{l}\text { Adjusted }= \\
\text { (per reactor) } \\
\text { Societal Risk } \\
\text { (\#/plant yr) }\end{array}$ & $\begin{array}{l}\text { Weighted } \\
(\#)\end{array}$ & $\begin{array}{c}\text { Weighted } \\
\text { Risk } \\
\text { (\#/plant yr) }\end{array}$ \\
\hline Early Fatalities & $3 \times 10^{-3}$ & $3 \times 10^{-5}$ & $1 \times 10^{6}$ & 30 \\
\hline Early Illness & $2 \times 10^{-1}$ & $2 \times 10^{-3}$ & $2.5 \times 10^{3}$ & 5 \\
\hline Delayed Fatalities & $7 \times 10^{-2} / y r$ & $2 \times 10^{-2}$ & $3 \times 10^{5}$ & 6300 \\
\hline Delayed IIlness & $7 \times 10^{-1}$ & $2 \times 10^{-1}$ & $2.5 \times 10^{3}$ & 500 \\
\hline Genetic Effects & $1 \times 10^{-2} / y r$ & $3 \times .10^{-3}$ & $1 \times 10^{4}$ & 30 \\
\hline Property Damage & $2 \times 10^{6}$ & $7 \times 10^{4}$ & 1 & $7 \times 10^{4}$ \\
\hline
\end{tabular}

(a) In the Reactor Safety Study, delayed effects are presented in terms of the total consequences divided by the plateau period to account for the fact that the effects would appear at this rate during the plateau period. However, in a steady state population of a large number of reactors, effects would be produced in any year that are the consequences of accidents that took place over a number of previous years. For example, if the delay period is 10 years and the plateau period is 30 years, then the cancers appearing in the year " $j$ " would be the result of accidents that occurred from $i-40$ to $i-10$. thus, it does not appear to be appropriate to divide by the plateau period. 
1. Although there is substantial controversy over the use of an equivalence between dollars and loss of life, this is a particularly convenient approach for illustrative purposes. In his study entitled "An Approach to Societal Risk Acceptance Criteria and Risk Management," David Okrent (1977) states that "Settlements in individual lawsuits for death or permanent disability fall mostly in the range

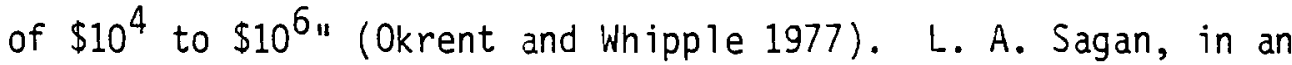
article appearing in the August 11, 1972, issue of Science assumes that the loss of one day's productivity is worth $\$ 50$. The U.S. Department of Labor, in a Labor Statistics Report (\#385,1969), has determined that a fatality represents the loss of 6,000 working days. Thus, an early fatality would have a "price tag" of $\$ 300,000$ in 1972. With inflation, that number has risen to nearly $\$ 550,000$ in 1980. Thus, a weight of $\$ 1 \times 10^{6} / 1$ ife is a reasonable value for use in this exercise.

2. Early illnesses associated with radiation exposure range from minor to very severe and may require only a visit to a physician or an extended hospital stay. According to statistics obtained from the Ohio State University Hospital, the average cost of a one-day hospital stay is $\$ 175$. If one assumes that the average time spent in the hospital for treatment of radiation sickness is 7 days and doubles the cost for other expenses, the average cost of an early illness is $\$ 2.5 \times 10^{3}$.

3. H. T. Davis (1977) estimates that the loss of life expectancy due to cancer fatalities is on the average $1 / 3$ the loss of life expectancy from early fatalities. On this basis, a weight of $\$ 3 \times 10^{5} / 1$ ife was selected. Note that this weight does not include any discounting of the value of a life with time.

4. Delayed illness has been given the same weight as early illness.

5. Genetic effects can have a wide range of influences on the affected individual from imperceptible to debilitating. It was felt that the 
weighting factor should be greater than for $i l$ lness but less than for a fatality. The value of $10^{4}$ was chosen somewhat arbitrarily.

6. The weight of the cost of property damage is taken as unity.

What do the results of Table 5.2 imply about the importance of different attributes? From a superficial interpreation, one would conclude that the most important risk from accidents in nuclear power reactors is property damage. The weighted risk of property damage appears to be an order of magnitude more important than the aggregated risk to human health. However, the concern about reactor safety voiced by members of the public does not arise from concern about property damage. The public is concerned about human health and in particular about the possibility of a nuclear accident resulting in a large number of fatalities. What then are the implications of Table 5.2? Does the public not understand the true character of the risks from nuclear accidents? Do they believe that the risks to public health are greater than estimated in WASH-1400 or do they have different values than are implied by the weighting system used for this example? The answers to these questions are not obvious. However, if risks are to be balanced against costs in a decision process, these questions must be answered. Using the WASH-1400 estimates of risk and the weighting factors from this example, the consideration of property damage would dominate the decision. Alternatives which minimized property damage, but not necessarily the impact on human health, would be favored. Is this the intent of the NRC? Is this the desire of the public? Should the public's perception of the magnitude of risk influence the decision process or should the decision maker rely on the judgment of specialists to estimate risk? Whose value system should form the basis for weighting attributes?

Another insight from Table 5.2 is that latent effects are probably a greater $r$ isk to the public than early fatalities. Some aspects of the analysis may tend to overemphasize the significance of latent fatalities, however. A large fraction of the estimated latent fatalities arises from low doses to a larger number of people. The linear approximation, which is used 
to estimate the increased probability of cancer incidence as a function of dose, is believed by many researchers to significantly overestimate the effect of low doses. In addition, latent cancer fatalities would occur at a future time dispersed among a large population. Thus, although the numbers of people affected could be large, the occurrence would not have many of the features of a catastrophe to which the public is particularly averse.

It is also interesting to compare the risk to the public from accidents in nuclear power plants to the health risk to workers from radiation exposure during normal operation. Based upon AIF data ("Occupational Radiation Dose Limits for Nuclear Facilities" 1980), the annual personnel exposure at an average plant is approximately 1,000 man-rem. Using BEIR ("The Effects on Populations to Exposure to Low Levels of Ionizing Radiation" 1972) coefficients to convert from man-rem to fatalities and a weighting factor of $\$ 3 x$ $10^{5} /$ fatality, the weighted risk is $6 \times 10^{4}$. Thus, the health risk to the workers appears to be an order of magnitude larger than that to the public and essentially equivalent to the risk of property damage. Since a tradeoff can exist between personnel exposure and reactor safety (e.g., through increased maintenance or inspection), the decision maker must be careful to account for all of the potential impacts of his actions.

\subsubsection{Who is at Risk?}

The people at risk from a nuclear accident vary in the distance from the reactor, time, and age group. Figure 5.1 from the German Risk Study (1978) shows the spatial dependence of risk for early fatalities and latent cancers. The risk of early fatalities falls off very rapidly with distance. Using the results Maekawa found in his doctoral thesis in $1976,80 \%$ of the societal risk of early fatalities lies within 5 miles of the plant. On the basis of individual risk, the likelihood of an individual who lives near a plant dying from radiation sickness in an accident is extremely small $\left(\sim 10^{-8} / \mathrm{yr}\right)$ even if his house is on the perimeter of the site. The individual risk falls off exponentially with an e-folding distance of 1.7 miles. Thus, if the estimated risks are within orders of magnitude of being correct, a member of the general public would be seriously misguided to worry about dying from radiation sickness in a nuclear accident. 
As shown in Figure 5.1 the risk of latent cancer falls off much more slowly with distance. Based on the German Study, the individual risk decreases approximately inversely as distance to the 0.85 power. As a result, the risk is spread among a much larger number of people than for early fatalities.

Different age groups are more or less sensitive to radiation exposure. As illustrated in Table VI.9-3 in the Reactor Safety Study, children are more seriously affected by a given dose than are adults. The only remarkable difference in sensitivity, however, is for unborn infants.

Consequences of a nuclear accident can appear immediatey in the exposed population, after a delay period in the exposed population, or in future generations as genetic defects. As indicated in Table 5.2 genetic effects do not appear to be as important as latent fatalities regarding their expected total impact on population.

In conclusion, the risk to human health, which is dominated by latent cancer fatalities, is fairly equitably distributed among the population receiving the benefits. Children bear a somewhat disproportionate share of the risk, but except for fetuses, the differences in sensitivity are small in comparison to the uncertainties in the risk. Although some consequences are carried over into future generations, as genetic defects, the associated risk is comparatively small.

\subsubsection{How Does the Timing of Consequences Affect Their Value?}

Life shortening has already been described as a means to consider early fatalities and delayed fatalities on a common basis related to the effects of each on life expectancy. In weighting the time dependence of consequences, it may also be appropriate to include human values for near-term and long-term deaths by use of a discount rate. This is a particular problem in performing risk/benefit analyses for very long-term projects such as geologic waste disposal in which postulated deaths could be very $f a r$ in the future. The proper value for a discount rate which would reflect social values is subject to debate. How much does a society value one death today versus one death 30 years in the future? Some people strongly feel that deaths should not be discounted at all. 


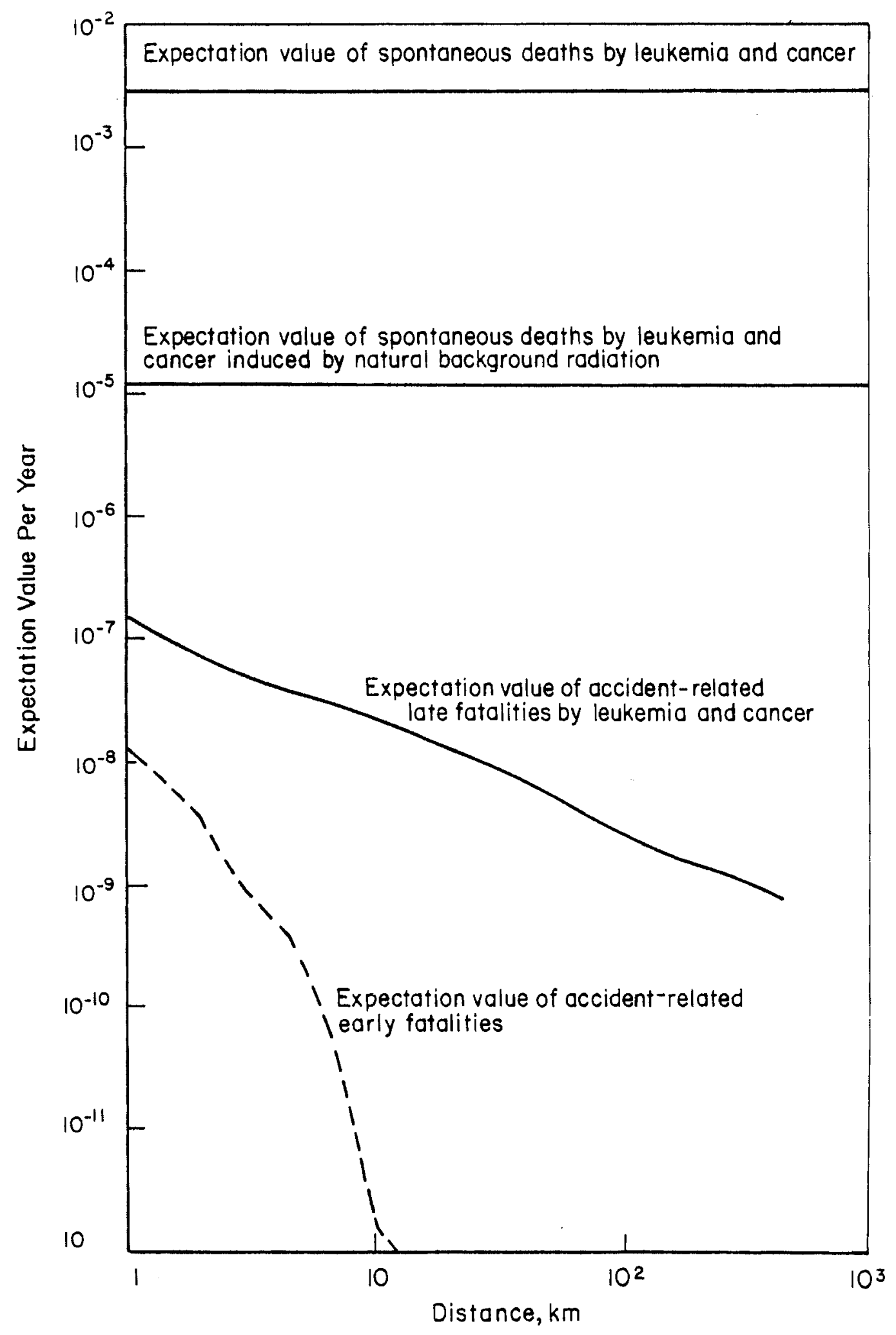

FIGURE 5.1. Spatial Dependence of Risk 
Using the following equation the effect of discounting on delayed consequences $c$ an be calculated.

$$
D=\sum_{i-1}^{p} \frac{1}{p} \frac{1}{(1+r)^{i+d}}
$$

where

$D=$ the discounted impact of the latent fatality

$p=$ the plateau period (i.e., the period over which the fatalities occur)

$r=$ the discount rate

$d=$ the delay period (i.e., the period between the accident and the first latent cancer fatality).

A discount rate of zero indicates that the impact of a latent fatality is the same as that of an early fatality, and the value of $D$ is one. If the discount rate is greater than zero, the impact of a fatality decreases with time, and $D$ is less than one.

By varying the values of $r, d$, and $p$ the sensitivity of $D$ to each parameter can be determined. Values of the discount rate, $r$, ranged from $1 \%$ to $10 \%$ while the plateau period, $p$, varied from 20 to 30 years, and the delay period, $d$, from 10 to 20 years. Only integral values were used. The results are presented in Figure 5.2 .

When the discount rate and delay period are held constant, the impact decreases slightly with an increasing plateau period. Similarly, when the discount rate and the plateau period are held constant, the impact decreases slightly as the delay period increases. However, the impact is extremely sensitive to the discount rate. As $r$ increases from $1 \%$ to $10 \%$, the impact drops sharply.

\subsubsection{How Do Uncertainties Affect the Use of Risk in Decision Making?}

In the Rector Safety Study the uncertainties in the risk curves were estimated as factors of 5 up or down in the probability dimension. The Lewis 

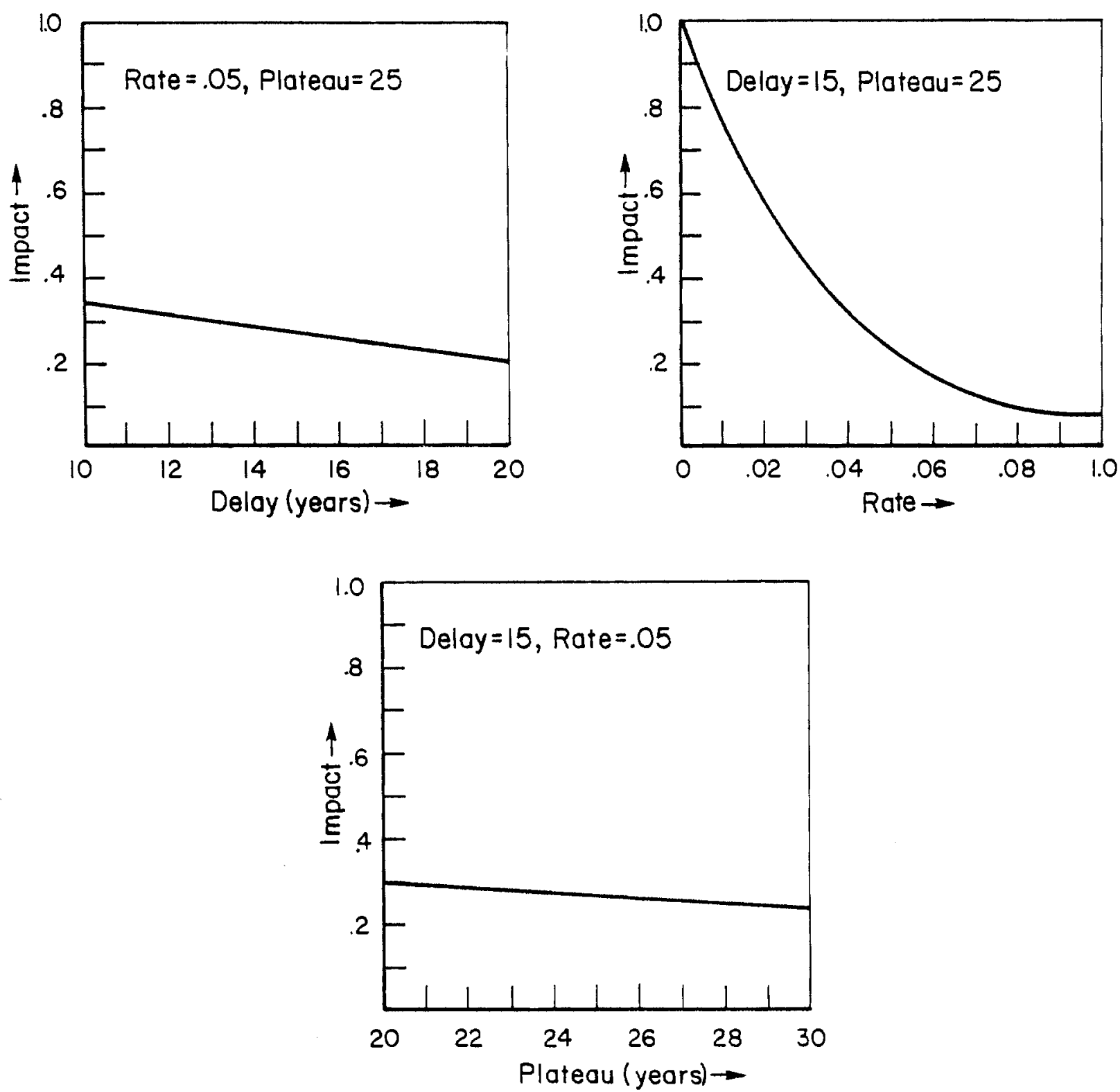

FIGURE 5.2. Discounted Fatalities as a Function of Delay Period, Plateau Period, and Discount Rate

Committee (Lewis et a1. 1978) has criticized these uncertainty bands as too narrow. The criticism is almost certainly valid because of the limited consideration of sources of uncertainty in the study. The uncertainty bands in the German Risk Study, however, are not appreciably larger than those in the Reactor Safety Study. The degree of uncertainty increases with the magnitude of the consequences. 
In the estimation of reactor risk, two types of uncertainty are encountered. These are listed as follows.

- random - Variation associated with different possible states of variables that $c$ an be encountered depending on timing or circumstances of the accident.

- systematic - Uncertainty resulting from ignorance of the true value of a parameter.

For example, if a major release of reactivity were to occur, the consequences of the accident would be very sensitive to the existing meteorological conditions such as wind velocity, wind direction, stability class and precipitation. By measuring these conditions at a site over a number of years, it is possible to characterize the probabilities associated with these conditions. In the categorization of uncertainties described above, these sources of variation are termed random. In calculating the probability density function for consequences (the risk), the known density function for the random variables are used in the analysis and determine the shape of the risk curve.

The systematic sources of error, on the other hand, instead of being incorporated in the risk curve should be reflected as uncertainty bands on the locus of the risk curve. For example, a major source of uncertainty in risk analysis is in the probability of an accident sequence leading to core meltdown. This probability is normally determined by fault tree analysis based on a number of probabilities at lower levels of the tree that can only be roughly estimated. The associated uncertainty should therefore, contribute to the uncertainty band for the calculated risk curve.

J. W. Litchfeld et al. (1976) in their paper "A Research and Development Decision Model Incorporating Utility Theory and Measurement of social Values" show how probability density functions for consequences (probability vs. attribute level) can be combined with utility functions (weight vs. attribute level) to produce a density function for utility (probability vs. weighted attribute level) for a particular attribute. Using weights for combining different attributes a density function can then be developed for all of the attributes weighted and aggregated. The weighted and aggregated attributes 
are termed total utility or total worth. The density function can then be integrated to obtain a cumulative distribution function or, as is more frequently used in risk analysis, a complementary cumulative distribution function. In Figure 5.3, reproduced from Litchfield's paper, cumulative distribution functions for seven alternatives are shown as a function of total utility. By comparing the distribution functions directly, the decision maker is better able to select among alternatives than if he had only an integral quantity such as the expectation value.

This method does not account, however, for the large uncertainty bands associated with the density functions obtained in risk analysis. If the uncertainty bands are carried through the analysis, then, as illustrated in Figure 5.4, the decision maker would have not only a distribution function for each alternative but also a confidence interval about each distribution function. If the confidence intervals overlap, it may be difficult for the decision maker to make a meaningful selection among alternatives.

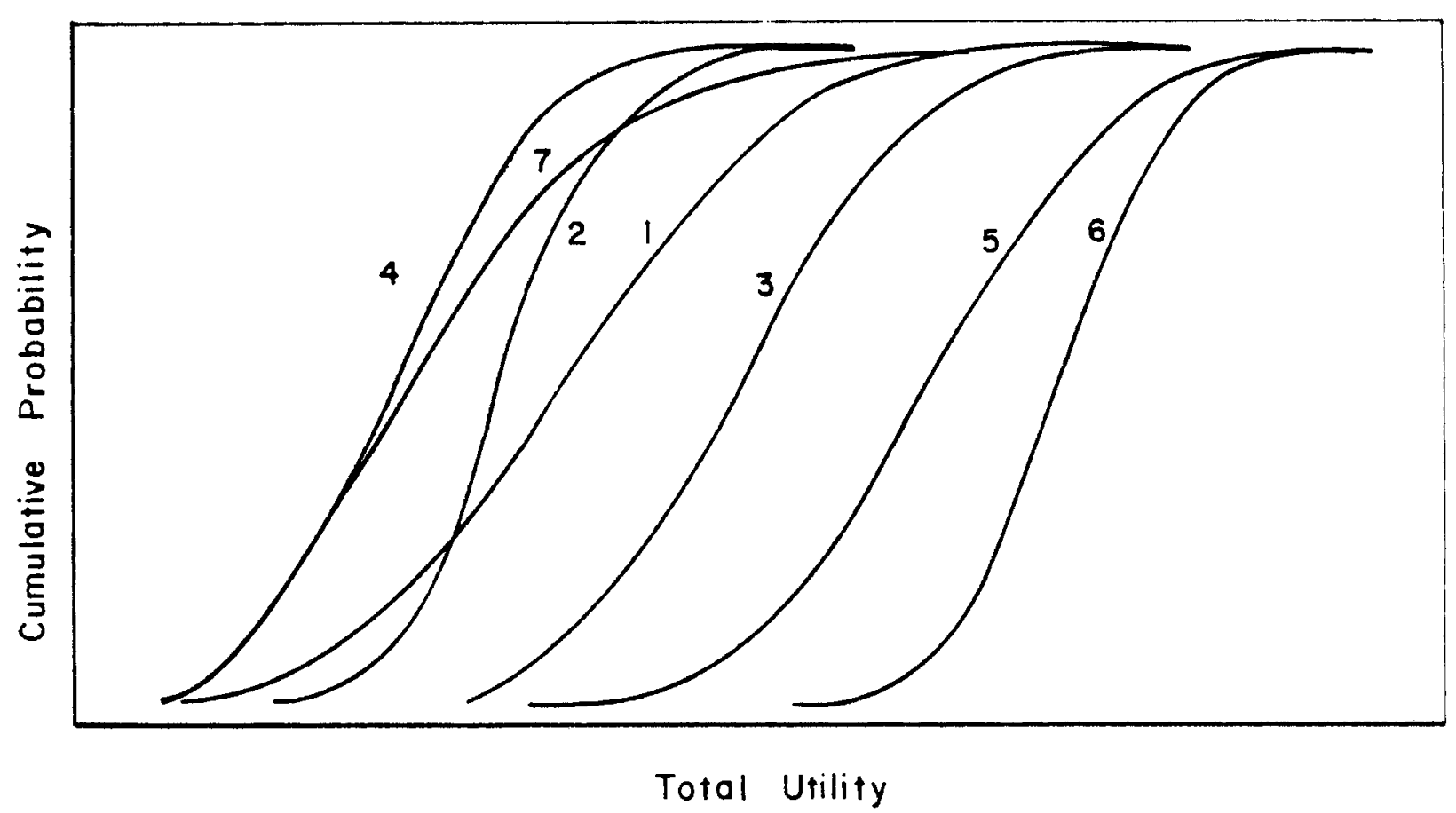

FIGURE 5.3. Cumulative Probability Distribution Functions on total Utility for Seven Alternatives (Litchfield 1976) 




FIGURE 5.4. Distribution Functions for Weighted Consequences with Confidence Intervals 


\section{REFERENCES}

Asselin, S. V., et a1. May 1978. "System Event Tree Analyses for Determin ing Accident Sequences that Dominate Risk in LWR Power Plants." Proceedings of the Topical Meeting on Probabilistic Analys is of Nuclear Reactor Safety, May $8-10$, 1978 .

Baecher, G. B., et a1. 1975. Balancing apples and Oranges: Methodologies for Facility Siting. RR-75-33, International Institute for applied Systems Analysis, Schloss Larenburg, Austria.

Carlson, D. C. 1978. A Methodology for Value-Impact Assessment of Nuclear Regulatory Research Programs. Sandia Laboratories, Albuquerque, New Mexico.

Carlson, D. D., and J. W. Hickman. June 1978. A Value-Impact of Alternative Containment Concepts. NUREG/CR-0165, National Technical Information Service, Springfield, Virginia.

Cohen, B. L., and I. Lee. 1979. "A Catalog of Risks." Health Physics, $36: 707-722$.

Davis, H. T. 1977. A Competing Risk Model for Reduction in Life Expectancy from Radiogenic Latent Cancer. SAND77-1352C, Sandia Laboratories, ATbequerque, New Mexico.

Lewis, H. W., et al. September 1978. Risk Assessment Review Group Report to the U.S. Nuclear Regulatory Commission. NUREG CR-0400, National Technical Information Service, springfield, Virginia.

Litchfield, J. W., J. V. Hansen, and L. C. Beck. June 1976. "A Research and Development Decision Model Incorporating Utility Theory and Measurement of Social Values." IEEE Transactions on Systems, Man, and Cybernetics, Vol. SMC -6 , No. 6 .

Lofgren, E., et al. 1980. "Application of Partial Failure Analysis to an Accident Involving Loss of Cooling in a Spent Fuel Storage Pool." ANS/ENS Topical meeting on Thermal Reactor Safety.

Lofgren, E., et al. 1980. "Application of Partial Failure Analys is to an Accident Involving Loss of Cooling in a Spent Fuel Storage Pool." ANS/ENS Topical Meeting on Thermal Reactor Safety.

Maekawa, M. July 1976. "A Method for Risk Analysis of Nuclear Reactor Accidents." Doctoral Thesis, Massachusetts Institute of Technology, Cambridge, MA.

Mur ley, T. E. 1980. "The NRC Nuclear Safety Research Program." ASN/ENS Topical Meeting on Thermal Reactor Safety. 
"Occupational Radiation Dose Limits for Nuclear Facilities." February 1980. ANS Document PPS-4.

Okrent, D., and C. Whipple. 1977. An Approach to Societal Risk Acceptance Criteria and Risk Management. UCLA School of Engineering and Applied Science, Los Angeles, California.

Powers, G. J., F. C. Tompkins, and S. A. Lapp. 1975. "A Safety Simulation Language for Chemical Processes: A Procedure for Fault Tree Synthesis." Reliability and Fault Analysis. SIAM.

Rasmussen, N. C. 1975. Reactor Safety Study: An Assessment of Accident Risk in U.S. Commercial Nuclear Power Plants. WASH-1400, U.S. Nuclear Regulatory Commission, Washington, D.C.

"Reporting the Progress of Resolution of 'Unresolved Safety Issues' in the NRC Annual Report." November 1978. SECY-78-6166.

Sagan, L. A. 1972. "Human Costs of Nuclear Power." Science, August 11, 1972, Vol. 177, p. 487.

"The Effects on Populations of Exposure to Low Levels of Ionizing Radiation." November 1972. Report of the Advisory Committee on the Biological Effects of Ionizing Radiations, National Academy of Sciences.

"The German Risk Study." August 1979. Gesellschaft fur Reaktorsicherheit.

U.S. Department of Labor. 1969. Work Injuries in Atomic Energy, Bureau of Labor Statistics Report No. 385, U.S. Government Printing Office, Washington, D.C.

U.S. Nuclear Regulatory Commission. 1978a. Anticipated Transients without Scram for Light Water Reactors. NUREG-0460, National Technical Information Service, Springfield, Virginia.

U. S. Nuclear Regulatory Commission. 1978b. Plan for Research to Improve the Safety of Light-Water Nuclear Power Plants. NUREG-0438, National Technical Information Service, Springfield, Virginia. 


\section{BIBLIOGRAPHY}

Carlson, D. C., J. W. Hickman, and M. A. Taylor. 1977. Value/Impact Comparison of Alternate Containment Designs. Sandia Laboratories, Albuquerque, New Mexico.

Cohn, M., et al, Value Impact Analysis. 1979. EPRI P-1237, Science Application, Inc., Palo Alto, California.

Davis, H. T. 1977. A Competing Risk Model for Reduction in Life Expectancy from Radiogenic Latent Cancer. SAND 77-1352C, Sandia Laboratories, ATbuquerque, New Mexico.

Fabrikant, J. I. 1979. Perspectives of Decision-Making and Estimation of Risk in Populations Exposed to Low Levels of Ionizing Radiation. LBL-8667, Berkeley, California.

Farmer, F. R.(ed.) 1977. Nuclear Reactor Safety. Academic Press, Inc., New York.

Farmer, F. R. 1977. "Relationship Between Risk Assessment and Reliability Requirements." International Conference on Nuclear Systems Reliability Engineering and Risk Assessment, June 20-24, 1977, Gatlinberg, Tennessee.

Kelly, J. E., et al. 1087/ Sensitivity Assessments in Reactor Safety Analysis. Science Application, Inc., Palo Alto, California.

Litchfield, J. W., J. V. Hansen and L. C. Beck. 1976. "A Research and Development Decision Model Incorporating Utility Theory and Measurement of Social Values." IEEE Transactions on Systems, Man and Cybernetics, Vol. SMC -6 No. 6, page 400 .

Maekawa, M., W. E. Vesely, and N. C. Rasmussen. 1977. "An Application of Risk Analysis: Functional Relationships of Nuclear Risks." International Conference on Nuclear Systems Reliability Engineering and Risk Assessment, Gatlinberg, Tennessee.

Okrent, D. and C. Whipple. 1977. An Approach to Societal Risk Acceptance Criteria and Risk Management. UCLA School of Engineering and Applied Science, Los Angeles, California.

Okrent, D. 1977. A General Evaluation Approach to Risk-Benefit for Large Technological Systems and Its Application to Nuclear Power. UCLA School of Engineering and Applied Science, Los Angeles, California.

Okrent, D., (ed.), Risk-Benefit Methodology and Application, Some Papers Presented at the Engineering Foundation Workshop. September 22-26, 1975, Asitomar, California. 
Otway, H. J., J. Linnerooth and F. Niehaus. 1977. "On the Social Aspects of Risk Assessment." International Conference on Nuclear Systems Reliability Engineering and risk assessment, June 20-25, 1977, Gatlinberg, Tennessee.

Rasmussen, N. C. 1975. Reactor Safety Study: An Assessment of Accident Risk in U.S. Commercial Nuclear Power Plants. WASH-1400, U.S. Nuclear Regulatory Commission, Washington, D.C.

Sagan, L. A. 1972. "Human Costs of Nuclear Power." Science, August 11, 1972, Vol. 177, p. 487.

Smith, K. R. 1980. "Risk Analysis: Toward a Standard Method." Nuclear Societies Thermal Reactor Safety Meeting, April 8-11, 1980, Knoxville, Tennessee.

Starr, C., R. Rudmand, and C. Whipple. 1976. "Philosphical Basis for Risk Analysis." Annual Review of Energy, Vol. 1, pp. 629-662.

U.S. Department of Commerce. 1979. Accident Risks in Nuclear Facilities: A Bibliography with Abstract. U.S. Government Printing Office, Washington, D.C.

Vinck, W., et al. 1980. "Comparative Risk-Benefit-Cost Effectiveness in Nuclear and Alternate Power Sources: Methodology, Perspective, Limitations." Nuclear Societies Thermal Reactor Safety Meeting, April 8-11, 1980, Knoxville, Tennessee.

Wa11, I. B., et al. 1977. "Overview of the Reactor Safety Study Consequence Model." International Conference on Nuclear Systems Reliability Engineering and Risk Assessment, June 20-24, 1977, Gatlinberg, Tennessee.

Zivi, S. M. and E. P. Epler. 1977. Enhancing Public Acceptance of Nuclear Energy by Improving Reactor Safety Systems. Institute for Energy Analysis, Oak Ridge Associated Universities, Oak Ridge, Tennessee. 


\section{DISTRIBUTION}

No. of

Copies

\section{OFFSITE}

A. A. Churm

DOE Patent Division 9800 S. Cass Avenue

Argonne, IL 60439

2 NRC Division of Technical Information and Document Control Washington, DC 20555

2 DOE Technical Information Center U.S. Department of Energy P.0. Box 62

Oak Ridge, TN 37380

5 R. DiSalvo

U.S. Nuclear Regulatory Commission

Office of Nuclear Regulatory Research

Washington, DC 20555

45 W. E. Vesely

U.S. Nuclear Regulatory Commission

Office Nuclear Regulatory Research

Division of systems and Reliability Research

Methodology and Data Branch

Washington, DC 20555
No. of

Copies

ONSITE

$3 \quad$ HARC

23 Pacific Northwest Laboratory

A. D. Chockie

M. J. Clausen (5)

D. W. Fraley (8)

R. C. Liikala

J. W. Litchfield

Technical Information (5)

Publishing Coordination KE (2)

Distr. 1 
